NBER WORKING PAPER SERIES

\title{
CONSUMER PROTECTION IN AN ONLINE WORLD: AN ANALYSIS OF OCCUPATIONAL LICENSING
}

\author{
Chiara Farronato \\ Andrey Fradkin \\ Bradley Larsen \\ Erik Brynjolfsson \\ Working Paper 26601 \\ http://www.nber.org/papers/w26601 \\ NATIONAL BUREAU OF ECONOMIC RESEARCH
1050 Massachusetts Avenue
Cambridge, MA 02138
January 2020
}

We thank Stone Bailey, Felipe Kup, Ziao Ju, Rebecca Li, Jessica Liu, Ian Meeker, Hirotaka Miura, Michael Pollmann, Nitish Vaidyanathan, and Chuan Yu for outstanding research assistance. We thank the company employees for sharing data and insights and participants at ASSA 2018, Boston University, Collegio Carlo Alberto, FTC Microeconomics Conference, INFORMS Revenue Management and Pricing Conference, Institute for Industrial Research Stockholm, Lehigh University, NBER PRIT 2019, Marketing Science Conference, Platform Strategy Research Symposium, SITE 2019 Occupational Licensing Conference, SOLE 2019, WISE 2018, and ZEW ICT for comments. We acknowledge support from grants through the Hellman Foundation, the Laura and John Arnold Foundation, the Russell Sage Foundation, and the MIT Initiative on the Digital Economy. The company from which we obtained proprietary data reviewed the paper to make sure that confidential information was reported accurately. None of the authors have any material financial relationship with entities related to this research. The views expressed are those of the authors and do not necessarily reflect the views of the National Bureau of Economic Research.

At least one co-author has disclosed a financial relationship of potential relevance for this research. Further information is available online at http://www.nber.org/papers/w26601.ack

NBER working papers are circulated for discussion and comment purposes. They have not been peer-reviewed or been subject to the review by the NBER Board of Directors that accompanies official NBER publications.

(C) 2020 by Chiara Farronato, Andrey Fradkin, Bradley Larsen, and Erik Brynjolfsson. All rights reserved. Short sections of text, not to exceed two paragraphs, may be quoted without explicit permission provided that full credit, including $\odot$ notice, is given to the source. 
Consumer Protection in an Online World: An Analysis of Occupational Licensing

Chiara Farronato, Andrey Fradkin, Bradley Larsen, and Erik Brynjolfsson

NBER Working Paper No. 26601

January 2020

JEL No. J2,J44,K2,L15,L51,L88

\begin{tabular}{|c|c|}
\hline \multicolumn{2}{|c|}{ BSTRACT } \\
\hline \multicolumn{2}{|c|}{$\begin{array}{l}\text { We study the effects of occupational licensing on consumer choices and market } \\
\text { large online platform for residential home services. We exploit exogenous variation } \\
\text { which licenses are displayed on the platform to identify the causal effects } \\
\text { information on consumer choices. We find that the platform-verified licensing } \\
\text { professional is unimportant for consumer decisions relative to review ratings an } \\
\text { confirm this result in an independent consumer survey. We also use variation } \\
\text { stringency across states and occupations to measure the effects of licensing on agg } \\
\text { outcomes on the platform. Our results show that more stringent licensing re } \\
\text { associated with less competition and higher prices but not with any improvemen } \\
\text { satisfaction as measured by review ratings or the propensity to use the platform agai }\end{array}$} \\
\hline Chiara Farronato & Bradley Larsen \\
\hline Harvard Business School & Department of Economics \\
\hline Morgan Hall 427 & Stanford University \\
\hline Soldiers Field & 579 Serra Mall \\
\hline Boston, MA 02163 & Stanford, CA 94305 \\
\hline and NBER & and NBER \\
\hline cfarronato@hbs.edu & bjlarsen@stanford.edu \\
\hline Andrey Fradkin & Erik Brynjolfsson \\
\hline Boston University & MIT Sloan School of Managemen \\
\hline Rafik B. Hariri Building 595 & 100 Main Street, E62-414 \\
\hline Commonwealth Avenue & Cambridge, MA 02142 \\
\hline Boston, MA 02215 & and NBER \\
\hline fradkin@bu.edu & erikb@mit.edu \\
\hline
\end{tabular}




\section{Introduction}

Heated debates over the effects of occupational licensing date back hundreds of years, with a long treatise on the subject contained in The Wealth of Nations (Smith (1776)), and continue intensely today ${ }^{1}$ An occupational license is a restriction placed on who is allowed to perform certain types of services, requiring that practitioners meet licensing requirements in order to legally practice. These laws apply to a growing share of the US labor force and now affect nearly $30 \%$ of all workers. Over 1,100 occupations are licensed in at least one state (Kleiner and Krueger 2010). These occupations include electricians, contractors, interior designers, and even hair salon shampoo specialists. The stringency of the licensing requirements - and the range of specific tasks within a service category requiring or not requiring a license - varies widely from state to state.

There is limited empirical evidence on the effects of licensing restrictions on professionals, consumers, and market equilibrium. In the presence of information asymmetries, licensing may protect consumers from poor service outcomes, guaranteeing at least some minimum standards of quality and safety for consumers (as in the model of Leland 1979). On the other hand, these laws may raise consumer prices and increase rents for licensed professionals by restricting competition (as in the model of Pagliero 2011). The model of Shapiro (1986) demonstrates that the benefits of occupational licensing for some consumers may come at costs to other consumers who face higher prices due to licensing.

We study the magnitude of these costs and benefits using new data from a large online labor market where consumers can hire professionals for home improvement services. On the benefit side, we first demonstrate, using choice data, that consumers care greatly about the professional's price and online rating but care little about the professional's licensing status. We validate these results in a nationwide survey of consumers who recently bought home improvement services. We then combine data from the platform with data on occupational licensing regulations to find that more stringent licensing regimes do not improve transaction quality as measured by review ratings or the propensity of consumers to use the platform again. Both of these results suggest that the benefits of licensing in terms of service quality

\footnotetext{
${ }^{1}$ See, for example, discussions in the New York Times (Cohen 2016), Wall Street Journal (Zumbrun 2016), and Forbes (Millsap 2017).
} 
may not be large. On the cost side, we find that more stringent licensing regimes result in less competition and higher prices.

The platform we study works as follows. A consumer can post a request for a particular job. Professionals respond to this request with a quote. For each quote, the consumer can see the proposed price, measures of the professional's online reputation (such as a 1-5 star average rating from past customers and the number of reviews), as well as a badge indicating that the professional is licensed. This badge is only displayed if the professional has uploaded proof of licensure to the platform and after the platform has independently verified this information, which typically occurs with a lag. Depending on the specific project needs or the required professional qualifications, a service provider may need a license in some jurisdictions but not others.

These features of the market - and our transaction-level data from the platform - provide an unprecedented opportunity to study several features of occupational licensing. The data consists of over one million requests by consumers in hundreds of distinct service categories throughout the United States for over eight months 2 It comes directly from the company's databases, and allows visibility into most dimensions of the search and exchange process occurring through the platform. We discuss the data and institutional setting in section 2 .

In section 3 we analyze how consumers' decisions depend on the characteristics of professionals (their verified licensing status and online reputation) and their bids (prices). We begin with event studies that analyze a consumer's probability of hiring a professional surrounding the exact date on which the professional's uploaded licensing status is verified by the platform. We exploit a unique feature of our data that allows us to identify the causal effect on consumers' decisions from displaying the professional's verified licensing status. Professionals choose to upload proof of licensure, but this information is not displayed to consumers until a few days later when the platform verifies the licensure. In the data, we see the timestamp for the original uploading of licensure proof by the professional and the timestamp for the platform's verification. We use this variation in timing for our event studies and find no statistically significant change in the probability that a consumer hires a professional before vs. after the verification is posted. In contrast, we find a discontin-

\footnotetext{
${ }^{2}$ The exact number of requests, the actual time frame, and the name of the company are not revealed to protect company's confidential information.
} 
uous positive jump in the probability of hiring a professional following the first time that a professional receives a review, suggesting that consumers respond to online reputation characteristics of professionals and not to indicators of licensure. We also examine whether, around the time of their license verification or first review, professionals themselves change their behavior in terms of prices they charge or types of requests on which they bid, and we mostly find no evidence of changes in bidding behavior.

We then analyze consumer choices in a regression framework, where we regress consumers' choices to hire a given professional on an indicator for whether the professional has a verified licensing status, controlling for whether the professional has uploaded licensure proof, again allowing us to obtain the causal effect of the verified licensing signal. We also include price and online reputation measures in this regression (average star rating and the number of previous reviews). These variables may be correlated with unobservable characteristics of the job request and the professionals' quality. We address this concern through a number of additional bid-level controls, request-level fixed effects, and a novel instrumental variables strategy. In our regression framework, we find similar results to our event studies: consumers appear to value professionals' reputation and prices but not their licensing status.

In section 4 , we present the results of an original survey we conducted using a nationally representative panel of individuals who purchased a home improvement service within the past year. We find that the survey respondents typically list prices and reviews when they are asked about the factors that influenced their decision to hire a particular professional. In contrast, fewer than $1 \%$ of these respondents mentioned licensing status among the top 3 reasons for why they hired a given service professional. This provides further evidence that consumers may care more about prices and online reputation than licensing status. This finding may simply reflect consumers' beliefs that all professionals are licensed. We asked survey respondents whether they knew the licensing status of the professional they ended up hiring. Only $61 \%$ of consumers were sure that their service provider was licensed and, of those, a majority only found out when they signed their contract rather than during their search, suggesting that most consumers are not particularly knowledgeable of professionals' licensing at the time of their hiring decision. 
These results - that consumers appear to pay little attention to licensing - do not necessarily imply a null effect of licensing laws on equilibrium service quality or prices. In section 5 we consider these market level effects. We use the large heterogeneity in regulatory stringency across occupations and states to measure the effect of licensing regulation-rather than the effect of licensing signals - on market equilibrium. To do this, we combine information from Carpenter et al. (2017) with additional data we collected to create a measure of licensing stringency at the level of each state and occupation based on education, training, and other requirements of state licensing regulation. We regress a number of different outcome measures on this stringency index and on detailed controls for the requested jobs. The availability of such detailed information (such as the square footage of the house) is a particular advantage of our setting and data, allowing us to control for differences in the composition of requests across occupations and states with different licensing regimes that may independently affect outcomes.

We find that more stringent licensing laws are associated with less competition (fewer professionals bidding) and higher prices, but have no detectable effect on two proxies of customer satisfaction: a customer's online rating of the service provider and their propensity to use the platform again. An important caveat is that our data may not provide a full picture of the effect of licensing on quality. Our customer satisfaction metrics - online ratings and return to the platform - are unlikely to take into account factors that are unobservable to the consumer during the transaction, that may impact consumer safety in the long-run, or that may cause externalities on other individuals. We may also lack statistical power to detect extremely rare but costly mistakes made by service professionals.

Our paper points to the importance of digital technologies for the design of regulation. Online platforms allow many occasional providers to offer their services, with little scrutiny of their licensing status. At the same time online markets make it easy to rate providers through online reviews and provide other forms of feedback to the platform. Friedman (1962) and Shapiro (1986) argued that a well-functioning feedback system can be an effective substitute for licensing by reducing the need for upfront screening or quality certification. The advent of online reputation mechanisms may be providing just such a system (Cowen and Tabarrok 2015; Farronato and Zervas 2019). If low-quality service providers can be 
easily and quickly identified by consumers' past experiences, the cost and benefit trade-off of occupational licensing might tip towards reducing licensing regulation. Our work suggests that, at least for the setting of residential home improvement services, consumers pay much more attention to reputation measures than licensing signals and more stringent licensing laws impose costs on consumers in terms of higher prices, without corresponding benefits in terms of customer satisfaction.

Our paper is related to research studying whether occupational licensing laws protect consumers from poor service outcomes. Leland (1979) proposes a model where licensing restrictions aid in overcoming an Akerlof (1970) lemons problem faced by consumers of professional services. Perhaps surprisingly, empirical work has largely found non-positive effects of increased occupational licensing stringency. Previous studies find null or negative effects of more stringent licensing requirements on quality for electricians (Carroll and Gaston 1981), contractors (Maurizi 1980), dentists (Kleiner and Kudrle 2000; Carroll and Gaston 1981), accountants (Barrios 2019), physicians (Kugler and Sauer 2005), Uber drivers (Hall et al. 2019), and others. Timmons (2017) and Traczynski and Udalova (2018) find that expanding nurses' independence from physicians actually improves service quality ${ }^{3}$ In fact, findings that stricter licensing regulation improves quality are rare in the literature. Some positive effects on quality are associated with increased stringency in the market for teachers, with these effects accruing primarily to high-income areas (Larsen 2015). In our study, we are unable to detect quality benefits of higher licensing stringency for a wide variety of professions.

In contrast to most of the previous literature, which focuses on the effects of licensing on the labor market, our approach allows us to also measure how consumers respond to seeing a signal indicating that a professional is licensed across a variety of professions. Demand-side analysis related to licensing has received limited attention. Exceptions include the work of Harrington and Krynski (2002) and Chevalier and Scott Morton (2008) on funeral homes, and more recently Kleiner and Soltas (2019) who estimate negative welfare effects of occupational licensing. We focus on consumer choices within the digital platform setting, which

\footnotetext{
${ }^{3}$ In these studies the quality metric is consumers' access to service, and the decreased stringency comes through an increase in the professionals' scope of practice (i.e., in what services the professionals are allowed to legally perform).
} 
is already an important channel for finding service professionals and is likely to become more important over time. Our empirical strategies are enabled by the fact that digital platforms collect transaction data, which allows us to control for detailed characteristics of jobs and professionals in order to study individual effects of licensing signals on consumer decisions and the effects of licensing stringency on market outcomes.

Our work also relates to research on the effect of licensing laws on competition and rents for professionals in the licensed occupation. A near-universal finding is that increased stringency of licensing requirements raises wages and prices in the occupation (see, for example, Kleiner 2006, Pagliero 2010, Timmons and Thornton 2010, Law and Marks 2017, Timmons 2017, and Koumenta and Pagliero 2018, among others). Our study demonstrates that this effect can be seen even at the individual job level, not just in aggregate wages. Occupational licensing requirements have also been shown to reduce competition (Kleiner 2006) and harm professionals who are unable to meet licensing standards but whose services are nonetheless desirable to consumers, such as Vietnamese manicurists (Federman et al. 2006 ) or the recent case of hair braiders in South Dakota (Sibilia 2017). The previous literature has also documented additional potential costs as well as benefits of occupational licensing. For example, state-level licensing requirements may impose limitations on labor mobility (see, for example, Johnson and Kleiner 2017 , Kleiner and Xu 2019 , Buonanno and Pagliero 2019) and decrease productivity growth as a result. DePasquale and Stange (2016) provide some evidence against this hypothesis for nurses. Work by Law and Marks (2009), Blair and Chung (2018), and Koumenta et al. (2019) suggests that licensing laws can aid minority or immigrant workers in signaling quality to potential customers.

\section{Institutional Details}

The data comes from a large US-only online platform which operates in all 50 states and offers consumers access to professional service providers in a variety of categories, such as interior design, home renovation, and painting. The platform allows customers to submit a project request. Several professionals are then allowed to submit quotes, consisting of a price and textual details of the service. The quoted price is not binding, and the actual 
payment takes place off the platform.

A nontrivial fraction of service providers bidding on the platform submit information on their occupational license in at least one service category, and a large fraction of the services require a license in at least some jurisdictions. All of these features together - the nature of physical tasks often requiring occupational licenses, the prevalence of licensed professionals, and the bidding process - make this platform an ideal market for studying whether and how the knowledge of occupational licenses matter in markets where reputation and other information about professionals are readily available to consumers.

This marketplace is distinct from other websites, such as Yelp (Luca 2016), that primarily provide a directory of businesses and professionals with crowd-sourced reviews. It also differs from platforms matching consumers to professional freelancers providing digital services, such as Freelancer and Upwork (Pallais 2014), since projects on this platform are nearly all physical tasks. Finally, it differs from platforms such as Instacart or Amazon Mechanical Turk, which match consumers to service providers for tasks that require less professional training - typically physical tasks such as grocery pickup/delivery for Instacart, and virtual tasks such as image identification for Mechanical Turk (Cullen and Farronato 2015; Chen and Horton 2016) : $^{4}$

The platform works as follows. Interested professionals can join the platform and create a profile containing information about themselves and their services. They can also submit proof of a license to be verified by the platform. The platform then takes some time to verify the license. This process typically takes a few days with some variation across professionals. The median number of days between license submission and verification is 6 days, with a 5.5 mean and 3.3 standard deviation. According to conversations with platform employees, this variation in time-to-verification is not dependent on the characteristics of the professionals during our study period and is as good as random. 5 Timestamps for both the initial license submission and the subsequent verification are contained in our sample.

\footnotetext{
${ }^{4}$ See Horton (2010) for further discussion of online labor markets.

${ }^{5}$ Note that the verification process has changed over time within the platform. Our description reflects this process during the period for which we have data. Furthermore, professionals on the platform who do not display a license may still have a license but have just not reported it to the platform. The licensing effect we will measure in section 3 will be specifically the signaling value of displaying the license verified badge to consumers.
} 
An individual consumer requests a quote for a particular type of service, describing her needs using pre-specified fields as well as some additional open-ended fields. Professional service providers in the appropriate occupation who have profiles on the platform are then notified of the job request and may then place bids for the contract. A limited number of professionals are allowed to bid, and bids are passed on to the consumer on a first-come, first-priority basis. The professionals pay a fee to submit bids. As bids are submitted, the consumer can look up information about each of the bidders, and then may, if she chooses, select a service provider from among those bidders.

The information available to the consumer about each of the professionals submitting quotes varies by bidder, and may contain photos or detailed descriptions of the kind of work the professional has performed in the past. To some extent, the amount and type of information available depend on what the professional decides to share on the platform. A stylized depiction of a consumer's interface for choosing a professional is available in Figure 1. Importantly for our study, for each bidder, the consumer is able to see any licensing information reported by the bidder. This licensing information is prominently visible if it has been verified by the platform. The consumer is also able to see any reviews of the professional's past work for other consumers, along with a 1-5 star average rating, the number of the previous reviews, and the number of previous times the professional has been hired through this platform.

We define professionals as verified licensed professionals if they choose to upload proof of license to the platform and the platform verifies the validity of the license. There is a high degree of variation in the fraction of professionals who report a license to the platform, which is key to our empirical strategy. It is important to make two remarks. First, a professional who does not display the licensing badge might nonetheless have a professional license, and would be able to disclose this to consumers via other means - e.g. through private messages or by including it in the body of text on their profile. Second, depending on the profession, an unlicensed professional may still legally provide services, but might be restricted in how they refer to the services they offer. For example, in the case of interior designers in Florida, a professional is legally not allowed to refer to themselves as an "interior designer" without a license, and will often instead describe their work using terms like "interior decorator," 
Figure 1: Stylized Representation of the Platform

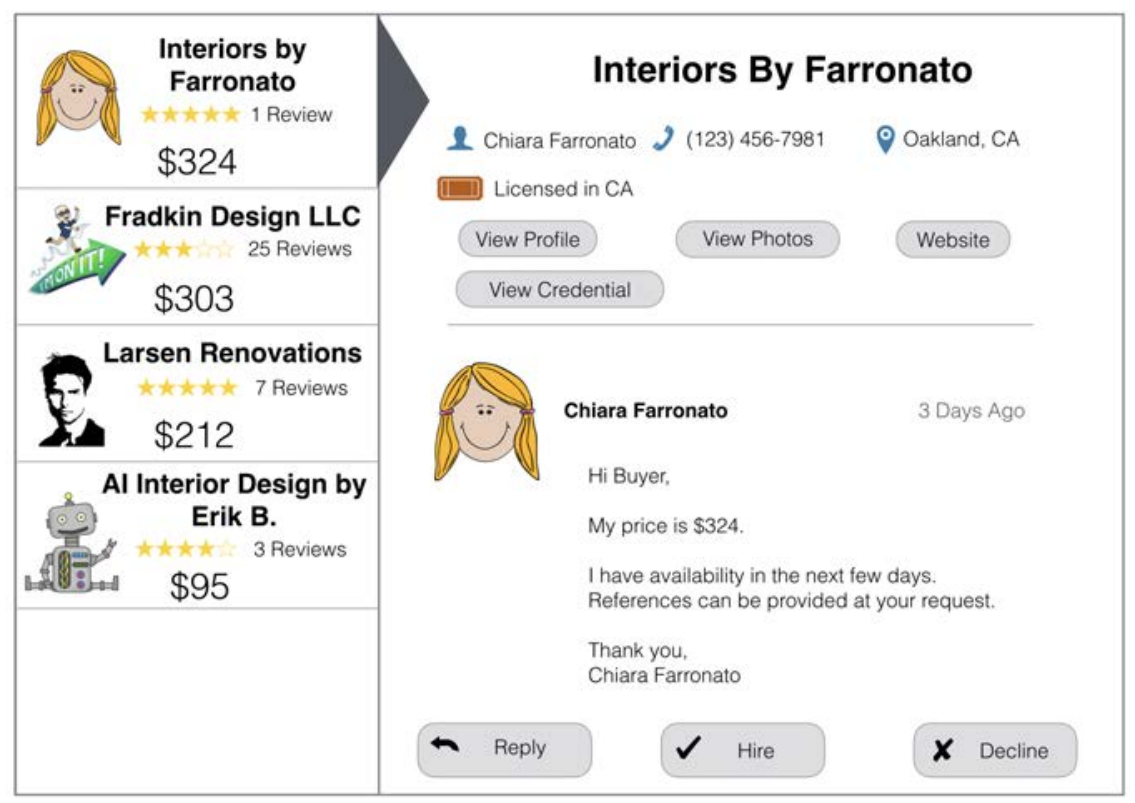

Notes: Reproduction of the information about professionals displayed on the platform. The layout and identity of the people displayed are products of the authors' imagination.

"interiors," or "organize your place." However, within the data, these professionals can still be identified as providing services similar to interior design. Unlicensed professionals may also provide services within a profession that typically requires a license if the project satisfies certain characteristics. For example, some states require professionals to have a license for commercial work - e.g., electrical work in a public building - but not for work in a private home. For general contractors in California, a license is only required if the payment for the services is over $\$ 500 \sqrt{6}$ Because of all these reasons, our results on the effect of the licensing badge on consumer choices section 3 should be interpreted as relating to the signaling value of the licensing information rather than the entire value of licensing regulation.

The main sample that we use contains the following restrictions. We first limit the sample by dropping home-improvement categories that never contain licenses (such as "closet organizing" or "IKEA furniture assembly"). We then drop any requests containing hourly

\footnotetext{
${ }^{6}$ We provide an analysis of the California regulation for general contractors in Appendix B
} 
price quotes below $\$ 10$ or above $\$ 250$, or containing fixed price quotes below $\$ 20$ or above $\$ 3,500$. We also drop a small number of requests in which more than one professional is recorded as having been hired (which are likely misrecorded) or requests that have received more than the maximum number of bids allowed by the platform.

We separately add sample restrictions for section 3 and section 5 . For section 3 we further constrain the sample to an eight-month period in 2015 for which we can observe both the timing of license submission by the professional and the license verification by the platform. We also drop any requests containing hourly price quotes (as opposed to fixed price quotes or bids with no price quote). For section 5 where we focus on the effect of licensing regulation on market outcomes, we drop requests if we have no task details provided by the consumer or data on occupational licensing regulation. Finally, we drop requests if there are only a few requests in a particular geography and service category. We discuss these sample restrictions in more detail in section $57^{7}$

\section{The Determinants of Consumer Choice}

In this section we study how professionals' licensing status, prices, and online ratings affect consumer choices of whom to hire. We offer two alternative approaches to analyze consumer sensitivity to licensing and reputation information: an event study approach and a regression analysis. Both approaches lead us to conclude that consumer choices are affected by online reputation and prices much more than by occupational licensing information.

We start with some descriptives. Table 1 displays summary statistics at the bid level for requests in our selected sample. Beginning with the licensing related variables, we see that $12 \%$ of bids are by professionals with a verified occupational license and $14 \%$ are by professionals who have uploaded proof of license. In theory, it is possible for professionals to signal their licensing status in ways other than the structured platform verification, such as through the text of their profile or the text of their quote, both of which the consumer can observe. We do not observe this information in our primary data sample; our analysis of consumer response to the licensing status of professionals will only focus on the formal licensing verification signal provided by the platform. In Appendix A we discuss an

\footnotetext{
Thable G.1 presents summary statistics for all requests, and for the selected samples used in our analysis.
} 
independent data sample that we constructed by web crawling the platform, in which we do see professionals' profile text. There we find that about $10 \%$ of professionals mention a license in their profile text and $6 \%$ have a license status verified by the platform.

Table 1 demonstrates that the median bid comes from a professional with 4 reviews, a rating of 4.9 stars, and a fixed price of $\$ 199$. $7 \%$ of bids result in a recorded hire and hired bids are made by professionals with more reviews and higher ratings, lower prices, and similar licensing-related variables as the typical bid. The platform relies on either customers or professionals to voluntarily mark a job as hired. This means that not all hires resulting from the platform will be recorded in the data and that some hires may not be accurately logged. We return to some of these issues in section 3 where we discuss our empirical specification.

Table 1: Summary Statistics: Bid Level

\begin{tabular}{|c|c|c|c|c|c|c|c|c|}
\hline \multirow[b]{3}{*}{ License Verified } & \multicolumn{5}{|c|}{ All Bids } & \multicolumn{3}{|c|}{ All Hired Bids } \\
\hline & Min & Median & Max & Mean & SD & Median & Mean & SD \\
\hline & 0 & 0 & 1 & 0.12 & 0.33 & 0 & 0.11 & 0.31 \\
\hline License Submitted & 0 & 0 & 1 & 0.13 & 0.34 & 0 & 0.12 & 0.33 \\
\hline Number of Reviews & 0 & 4 & 391 & 9.90 & 19.00 & 6 & 15.00 & 25.00 \\
\hline Average Rating & 1 & 4.90 & 5 & 4.70 & 0.49 & 4.90 & 4.80 & 0.35 \\
\hline Price & 20 & 199 & 3,500 & 402.00 & 572.00 & 125 & 259.00 & 396.00 \\
\hline Hired & 0 & 0 & 1 & 0.07 & 0.26 & & & \\
\hline
\end{tabular}

Notes: Bid-level summary statistics for the sample used to study consumer choice of service providers. After cleaning the data as described in section 2 we are left with $1,871,735$ bids.

\subsection{Event Study}

Our first approach to analyzing consumer choices is an event study. The platform data allows us to measure each opportunity that a professional has to get hired, as well as the hiring outcome. We consider the probability that a professional is hired for a job to which she submitted a bid around the time of license verification. If license verification positively affects consumer choices, then bids submitted a few days before license verification should have a lower chance of being chosen than bids submitted just after the license is verified (and thus visible to consumers). More formally, we regress an indicator for whether a professional was hired (hired) on dummy variables for the leads and lags relative to the 
license verification day. We also include professional fixed effects to control for unobserved heterogeneity across professionals, and request fixed effects to control for the particular request and amount of competition.

Our specification is the following:

$$
\text { hired }_{j r}=\sum_{t=-4}^{4} \beta_{t} * \mathbf{1}\left\{\text { diff }_{j r}=t\right\}+\text { submitted }_{j r}+\gamma_{j}+\mu_{r}+\epsilon_{j r},
$$

where $\operatorname{diff}_{j r}$ is the difference (in weeks) between the date of professional $j$ 's bid on request $r$ and the date professional $j$ 's license was verified by the platform. A bid is included in week 0 if it is submitted $0-6$ days after the license is verified; it is included in week 1 if it is placed 7-13 days after the license is verified; and so on. We consider weeks within an eight-week interval around platform verification, and include a dummy variable for whether a bid was submitted more than four weeks after license verification. The variable submitted $_{j r}$ is an indicator for whether professional $j$ has uploaded a license at the time of request $r$. Request fixed effects are denoted $\mu_{r}$, and professional fixed effects are denoted $\gamma_{j}$. The $\beta_{t}$ coefficients should be interpreted as hiring probabilities relative to the probability of being hired for a bid submitted more than four weeks prior to license verification. We cluster standard errors at the professional level 8

Figure 2a displays the estimated coefficients $\beta_{t}$ from Equation 1. We find no significant differences in the probability of being hired as a function of when the bid was placed relative to the time of license verification. The estimated coefficients also show no significant pretrend in the likelihood that a professional is hired prior to the license verification date, consistent with our assumption that the timing of verification is exogenous. Overall, the results suggest that consumers' decisions of whom to hire are not influenced by the visibility of licensing information, although the $95 \%$ confidence interval does not exclude effects on the order of a 1 percentage point change in hiring rates. In subsection 3.2 we use an alternative identification strategy which yields more precise estimates and confirms that knowing about a professional's licensing status does not substantially affect consumer decisions. We also

\footnotetext{
${ }^{8}$ For each request in the data, we also add an additional observation to the dataset representing the outside option; if the consumer in a given request does not hire any bidder, the hired dummy is equal to 1 in the outside option observation corresponding to that request. We follow this same procedure in our regression analysis in subsection 3.2 .
} 
Figure 2: Event Study Estimates-License Verification

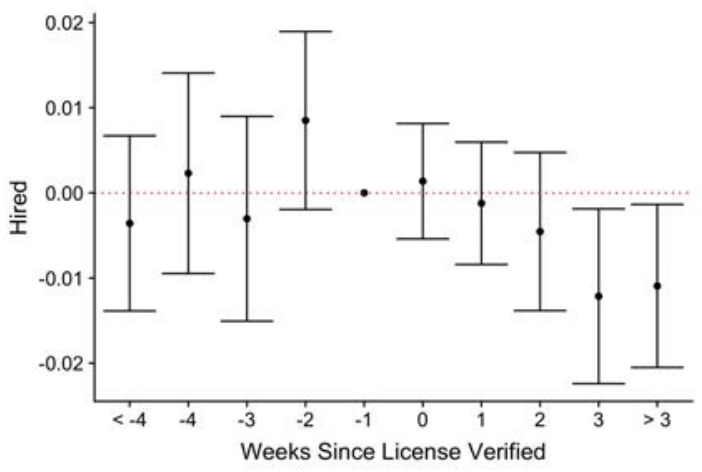

(a) Hired

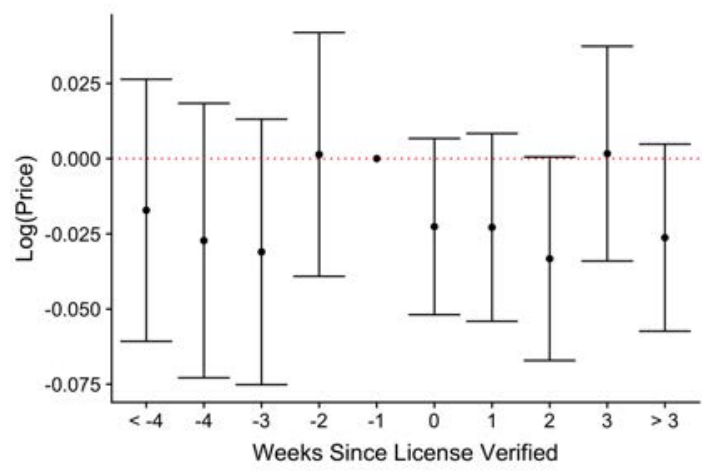

(b) $\log ($ Price $)$

Notes: Estimated coefficients from Equation 1 In the left panel the outcome variable is equal to 1 if the professional is hired. In the right panel the outcome variable is the log of the bid amount. Lines display $95 \%$ confidence intervals based on standard errors clustered at the professional level.

investigate whether there may be a positive effect of the license signal for professionals without a prior hire. We find suggestive but imprecise evidence of such an effect (see Appendix C).

One potential threat to the identification of the effect of displaying licensing information is that professionals may adjust their bidding behavior around the time of license verification. We examine this by repeating the estimation of Equation 1 using the professional's quoted price as the left-hand-side variable of interest (Figure 2b). We find no significant differences in bid prices across these time periods, suggesting that professionals do not appear to be bidding differently in anticipation of or after license verification. We also find no changes in the types of requests professionals bid on and the timing of these bids as a result of the license verification (see Appendix C).

To show that our empirical strategy would be able to pick up important determinants of consumer choices, we repeat the above exercise using the first review received by a professional as the relevant event. We use the first review because it is typically a 5-star review, so we do not need to differentiate between good and bad ratings 9 To be more precise, we estimate the same specification as in (1) but substitute the timing relative

\footnotetext{
${ }^{9}$ We find similar results when we instead consider the first five-star review received by the professional.
} 
to license verification with the timing relative to the submission of the first review. We exclude bids that lead to the first review in the specification so that there is no mechanical relationship between first review and hire.

Figure 3: Event Study Estimates-Reviews

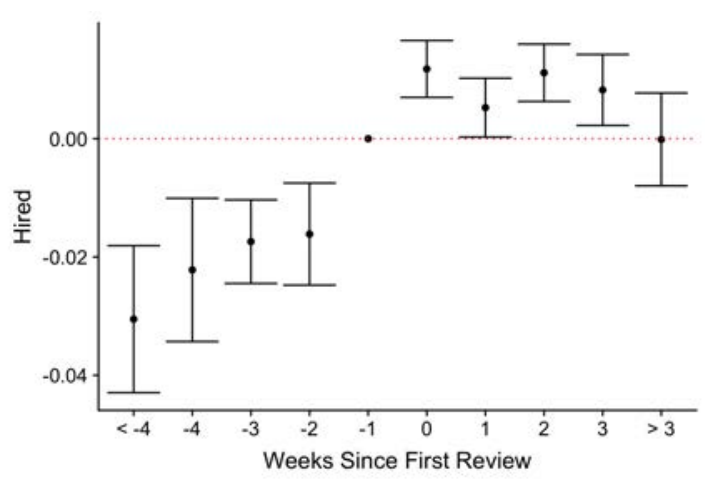

(a) Hired

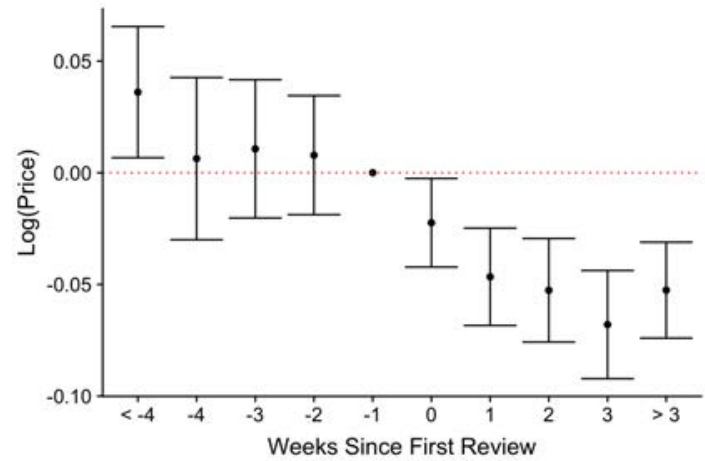

(b) $\log ($ Price $)$

Notes: Estimated coefficients from Equation 1] where the event is the time when a professional receives her first review on the platform. In the left panel the outcome variable is equal to 1 if the professional is hired. In the right panel the outcome variable is the $\log$ of the bid amount. Lines display $95 \%$ confidence intervals based on standard errors clustered at the professional level.

Figures $3 \mathrm{a}$ and $3 \mathrm{~b}$ display the estimated coefficients $\beta_{t}$ from the event study of the first review on hires and bids. We can see that there is a jump in hiring rates of 2.8 percentage points around the time of the first review and a smooth decline in prices around the focal date. The change in prices is more gradual, and thus unlikely to explain the discrete increase in hiring rates. It is worth noting that there seems to be a pre-trend in $3 \mathrm{a}$ with an increase in the hiring rate in the seven days preceding the first review. Our hypothesis for this effect is that customers may take some time to decide whom to hire, and their final decision for a given request may occur after the first review is revealed; if this is true, consumers' hire rates would appear to react to reviews several days before the arrival of the review.

To investigate this hypothesis, we re-estimate the event study using a closer approximation to the time at which the customer made a choice: rather than comparing the arrival time of the first review to the arrival time of the bid, we compare it instead to the time the customer first messaged the professional about this request. We also limit the sample to 
cases where the "hired" button was clicked by the customer rather than by the professional; the professional might be strategic in timing when to click this button, and the customer's timing might more accurately reflect the timing of the decision 10 Note that this sample is substantially smaller and we consequently get wider confidence intervals. The results are displayed in Figure 4a, where we find much less of a pre-trend, and we see a sharp, 10 percentage point increase in the hire probability following the display of the first review. Note that the effect size is bigger in this sample because the baseline hiring rate is much higher. There is no similar discontinuity in professionals' quoted prices around the time of the first review (Figure $4 \mathrm{~b})$, suggesting that professionals are not discontinuously changing their pricing behavior surrounding this event. Appendix D discusses additional event studies that suggest that the effect of reviews on hiring does not seem to be driven by supply side responses and that the effect of the first review is driven by first reviews with high ratings.

Figure 4: Event Study Estimates-Reviews (Alternative Timing and Subsample )

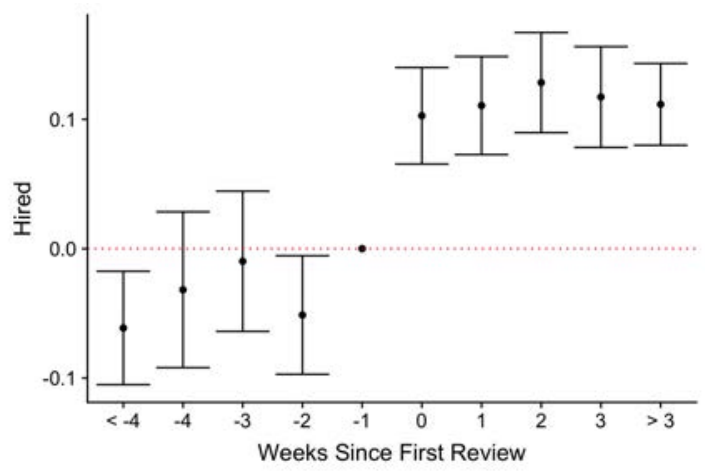

(a) Hired

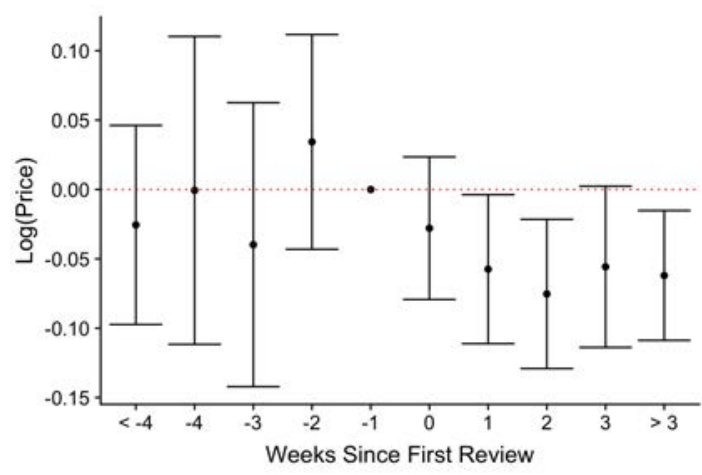

(b) $\log ($ Price $)$

Notes: The figures plot results similar to Figure 3 except for two changes. First, we restrict the sample to requests in which the customer (not the professional) clicked on the "hire" button. Second, the weeks are defined as the time when the customer first messaged the professional (rather than the time when the professional submits her bid) relative to the time of the first review. Lines display $95 \%$ confidence intervals based on standard errors clustered at the professional level.

\footnotetext{
${ }^{10}$ Either the professional or the customer is allowed to click the "hired" button.
} 


\subsection{Choice Regressions}

We now present a regression framework for measuring the effects of displaying professionals' reported licensing status and the effects of professionals' prices and online reputation on consumer choices. For professional $j$ 's bid on request $r$, we specify the indicator for whether $j$ gets hired as follows:

$$
\begin{gathered}
\text { hired }_{j r}=\beta_{0}+\text { submitted }_{j r} \beta_{1}+\text { verified }_{j r} \beta_{2}+\log \left(\text { price }_{j r}+1\right) \beta_{3}+ \\
\log \left(\text { reviews }_{j r}+1\right) \beta_{4}+\text { avg_rating }_{j r} \beta_{5}+X_{j r}^{\prime} \beta_{7}+W_{j r}^{\prime} \beta_{8}+\varepsilon_{j r}
\end{gathered}
$$

As in the event study, we control for the license submission decision (submitted $_{j r}$ ). This indicator is visible to us in the data, but the professional's reported license status is not visible to the consumer until verified verified $_{j r}=1$ ). We can then interpret the coefficient $\beta_{2}$ on the verified variable as the causal effect on the hiring probability of the consumer knowing that a professional is licensed. The variable price $_{j r}$ is professional $j$ 's quoted price for request $r$; reviews ${ }_{j r}$ represents the number of reviews the professional has received before submitting a quote on request $r$; and avg_rating $_{j r}$ is $j$ 's average star rating (1-5) at the time of submitting the bid on request $r$. The vector $X_{j r}$ includes an indicator for whether the quote is missing a price (in which case price $_{j r}$ is also set to zero), an indicator for whether reviews $_{j r}=0$, an indicator for whether an observation corresponds to the outside option bid (see subsection 3.1), and a flexible set of controls for the time of a request relative to the license submission time.

The vector $W_{j r}$ differs depending on our specification. In our simplest specification (Column 1 of Table 2), $W_{j r}$ is omitted. In columns 2, 4, and 6, we include in $W_{j r}$ a quadratic term for the time the professional has been registered on the platform; the character length of the text of the professional's quote (and a dummy for whether this text length is missing); indicators for whether the professional has a business license submitted and whether this business license is validated (a business license is distinct from an occupational license); indicators for whether the professional's profile has pictures, has a website link, lists the number of employees, and provides a date of establishment of the business; indicators for the arrival order of the bids for the request; and fixed effects for the month, state, and 
Table 2: Consumer Choice Regressions: Outcome $=$ Hired

\begin{tabular}{lccccccc}
\hline \hline & $(1)$ & $(2)$ & $(3)$ & $(4)$ & $(5)$ & $(6)$ & $(7)$ \\
& OLS & OLS & OLS & Price IVs & Price IVs & All IVs & All IVs \\
\hline License Submitted & 0.00121 & 0.00458 & 0.00756 & 0.00292 & 0.00511 & 0.00621 & 0.00830 \\
& $(0.00401)$ & $(0.00392)$ & $(0.00495)$ & $(0.00602)$ & $(0.00889)$ & $(0.00558)$ & $(0.00807)$ \\
License Verified & & & & & & & \\
& 0.00127 & 0.000906 & 0.00325 & 0.00235 & 0.0147 & 0.00289 & $0.0147^{*}$ \\
& $(0.00399)$ & $(0.00377)$ & $(0.00530)$ & $(0.00801)$ & $(0.00937)$ & $(0.00696)$ & $(0.00861)$ \\
Average Rating & & & & & & \\
& $0.0205^{* * *}$ & $0.0200^{* * *}$ & $0.0283^{* * *}$ & $0.0236^{* * *}$ & $0.0333^{* * *}$ & $0.175^{* * *}$ & $0.254^{* * *}$ \\
& $(0.000930)$ & $(0.00106)$ & $(0.00429)$ & $(0.00316)$ & $(0.00692)$ & $(0.0564)$ & $(0.0846)$ \\
Log(Reviews +1$)$ & $0.0144^{* * *}$ & $0.0220^{* * *}$ & $0.0311^{* * *}$ & $0.00591^{* *}$ & 0.00458 & 0.00401 & -0.000908 \\
& $(0.000892)$ & $(0.00411)$ & $(0.00648)$ & $(0.00287)$ & $(0.00380)$ & $(0.00420)$ & $(0.00590)$ \\
& & & & & & \\
Log(Price + 1) & $-0.0287^{* * *}$ & $-0.0369^{* * *}$ & $-0.0543^{* * *}$ & $-0.433^{* * *}$ & $-0.695^{* * *}$ & $-0.366^{* * *}$ & $-0.617^{* * *}$ \\
& $(0.00103)$ & $(0.00846)$ & $(0.0111)$ & $(0.0392)$ & $(0.0557)$ & $(0.0336)$ & $(0.0482)$ \\
\hline$N$ & $2,669,083$ & $2,669,083$ & $2,669,083$ & $2,669,083$ & $2,669,083$ & $2,669,083$ & $2,669,083$ \\
Other Controls & No & Yes & Yes & Yes & Yes & Yes & Yes \\
State and Month FE & No & Yes & No & Yes & No & Yes & No \\
Category FE & No & Yes & No & Yes & No & Yes & No \\
Request FE & No & No & Yes & No & Yes & No & Yes \\
\hline \hline
\end{tabular}

Notes: Regression results from Equation 2 The first three columns use OLS and progressively add controls. The next two columns instrument for price, and the final columns instrument for having any rating, for the number of reviews, for the average rating, as well as for price. Table G.4 through Table G.6 show first stage results. Standard errors are clustered at the professional level. ${ }^{*} \mathrm{p}<0.1 ;{ }^{* *} \mathrm{p}<0.05 ;{ }^{* * *} \mathrm{p}<0.01$.

category of the request. In our most flexible specifications (columns 3,5 and 7 ), $W_{j r}$ includes request-level fixed effects.

Consistent with our event study analysis, in column 1 we find no effect of the licensing signal on the hiring choice (the coefficient on verified $_{j r}$ is a precise zero). We do find significant positive impacts for each of the reputation measures (average rating and number of reviews) and significant negative effects of prices. Each of these variables is potentially correlated with characteristics of the professional or the request. In columns 2 and 3 , we account for this possibility by including the additional controls described in the previous paragraph. Even with request-level fixed effects - which account flexibility for unobservable difficulty of the job requested by the consumer - we find very similar results.

Prices are likely also correlated with unobservables at the bid level not accounted for with our additional controls, such as time-varying dimensions of professional quality. To address this concern, in columns 4 and 5, we instrument for price in (2) using the geographic distance between the consumer's zip code and the professional's zip code. The majority of the services on the platform require working in the home of the consumer. This location 
requirement implies that the professional's costs should be increasing in this distance, but this distance is unlikely to directly affect the consumer's willingness to pay for the service 11 Column 4 displays the results with state, month, and category fixed effects and column 5 with request fixed effects 12 In each case we find a much larger magnitude for the price coefficient than in the OLS specifications, consistent with price endogeneity. We continue to find no significant effects of the licensing signal. We find significant positive effects for the professional's average rating in both columns 4 and 5 , but in column 5 we are no longer able to detect a positive effect for the number of reviews separately from the average rating effect 13

Similar to prices, the reputation measures in Equation 2 may be correlated with timevarying unobservables that relate to the quality of the professional. This could hinder a comparison of the license-verified effect and the online ratings effect. We therefore propose, as an additional specification, an instrumental variables strategy based on the work of Chen (2018). Specifically, we instrument for a professional's current rating using the ratings that the focal professional's raters (i.e. those who have rated the focal professional until now) assigned to other professionals. Similarly, we instrument for the professional's current number of reviews using the propensity of the focal professional's previous hirers (i.e. those who have hired the focal professional) to leave reviews on others whom they hired. We describe the construction of these instruments in Appendix E. Columns 6 and 7 display the results using these instruments in addition to the price instruments. We again see a large negative effect of price, and a significant and positive effect of average ratings (and no separate effect of the number of reviews). The IV estimate of the effect of average ratings increases by an order of magnitude. We continue to find no significant effect, or at best

\footnotetext{
${ }^{11}$ More precisely, we instrument for price with this distance measure, along with a dummy for whether the professional and consumer are in the same location and a dummy for whether the professional and consumer are more than 100 miles apart. One may be concerned that customers prefer professionals located very close to them, and indeed the survey evidence presented in section 4 suggests that customers care about whether the professional is "local". Adding to the second stage a dummy variable for whether the professional is located in the same zip code as the consumer and a dummy variable for whether they are located more than 100 miles away does not change our results.

${ }^{12}$ First stage estimates corresponding to columns 4 and 5 are found in Table G.4 and first stage estimates for columns 6 and 7 are found in Table G.5 and Table G.6 respectively.

${ }^{13}$ In all of our specifications, we do not separately control for the professional's number of previous hires and number of reviews, as these two variables move closely with one another and identifying a separate effect of these two signals is challenging.
} 
only marginally significant effect of license verification.

The bulk of the evidence from Table 2 suggests that there is no significant impact of displaying the verified license signal. On the other hand, in all our specification, we find positive effects of average ratings and negative effects for prices (and, in our first four specifications, a positive, significant effect for the number of reviews). However, for the sake of comparison, taking the 1.47 point estimate of the license verified effect (from column 7) at face value and comparing it to the price effect (-0.617) suggests that the licensing signal is worth a drop in price from $\$ 200$ (the median in our sample) to about $\$ 197$. And comparing to the average rating coefficient (0.254) suggests that the licensing signal is worth about 0.06 of a star.

In Table G.3 we offer alternative versions of specification 7 from Table 2 in which we interact the license variables with a number of other variables. We find no evidence that a consumer values a professional's license status more if the consumer lives in a state with a more stringent licensing regime for the job in question; if the consumer has never previously posted a request or hired on the platform before; if the professional has no previous ratings; of if the job is one that tends to be more expensive. We do find that consumers value a license more for requests that receive bids by at least one licensed and one non-licensed professional. Figure G.1 displays estimates of the license effect, price effect, and reputation effects from estimating specification 7 separately by job category, where we find similar results to those in Table $2{ }^{14}$ We interpret our overall findings thus far as suggesting that knowledge of a professional's licensing status does not substantially impact consumer choices. In contrast, we find that reputation measures and quoted prices have important effects on hiring probabilities 15

\footnotetext{
${ }^{14}$ In Figure G.1 we focus on aggregated meta-categories, as defined in the notes to the figure. We find that the estimated coefficients differ by meta-category. We find multiple meta-categories with significant negative effects of prices or significant positive effects of ratings and the number of reviews (and no meta-categories with the reverse), and we find no meta-categories with significant positive effects of the license verified signal.

${ }^{15}$ We find very similar effects to those shown in Table 2 when we use a conditional logit model instead of a linear probability model. Marginal effects from this model are shown in Table G.2 where we estimate regressions corresponding to columns 3, 5, and 7 of Table 2 Table G.2 also displays results from a linear probability model as in Table 2 but with fixed effects for each professional; we do not prefer these regressions because there is little variation within a given professional over time with which to identify our effects of interest, and our first stage estimates for our average rating IV are not significant after controlling for professional fixed effects.
} 


\section{Survey Evidence}

To dive deeper into how consumers think about (or don't think about) licensing when making choices, we conducted a survey of a nationally representative sample of customers about their choices regarding home improvement professionals. Our survey panel was created by the service ProdegeMR and consists of 12,760 respondents, of whom 5,859 hired a home services professional within the past year and 5,219 of those fulfilled additional validation criteria to be considered a reliable response. The survey questions are available in Appendix F.

We first asked respondents about the service they purchased. The most common word stems include "paint" (10.1\%), "replac" (8.4\%), "plumb" (8.3\%), "repair" (7.6\%), "instal" (7.5\%), and "roof" (6.5\%). Broadly, the services purchased by the survey respondents mirror the services purchased on the platform. When we categorize the responses according to occupations, we find that the most common occupations include HVAC contractors (20\%), plumbers (19\%), and painting contractors (10\%).

Many consumers find their service providers online, validating the importance of studying consumer choices in online platforms. The modal way through which consumers find service providers is still word of mouth through a friend (53\%), but Google and Yelp are used by $25 \%$ of the respondents, and $16 \%$ say they used a platform like the one we study. Note that for those consumers who say they used Google, the exchange may in fact have been intermediated by digital platforms like the one we study. Overall, the shares suggest that the internet is an important way to find home improvement professionals 16

Survey respondents also care more about prices and reputation-online or word-ofmouth - than knowing about whether a professional is licensed. When asked to list up to 3 reasons for why consumers selected a particular professional, respondents' answers included the word stems "price" (50\%), "cost" (14\%) 17 "quality" (14\%), "review" (13\%), "recommend" (13\%), and "friend" (12\%) 18 Fewer than 40 respondents (less than 1\%) listed

\footnotetext{
${ }^{16} 15 \%$ of the respondents selected the 'Other' category, but then mentioned family and friends, Facebook, neighborhood, and professionals they hired previously as the way in which they found the current professional.

${ }^{17}$ An additional $6 \%$ of the responses included the words "cheap" and "afford".

${ }^{18}$ An additional $13 \%$ of the responses included "refer", and an additional $9 \%$ of the responses included "reput".
} 
licensing in their top 3 reasons for hiring a professional.

Respondents do not seem very knowledgeable about the occupational licensing status of their providers, at least during the search process. Indeed, $61 \%$ of the respondents knew that their chosen providers were licensed for the service requested, but $52 \%$ of those only found out only when they signed the contract, and $33 \%$ found out from the professionals telling them. More people found out about a professional's licensing status on a platform like the one we study $(9 \%)$ than on an official government website $(6 \%)$.

It may be the case that the customers who hire non-licensed professionals or do not know about the licensing status of the professional do so because they know that a license is not required for the service. To examine this possibility, we asked respondents whether a license was required by law for the service requested. $37 \%$ of the respondents said they were unsure whether a license was required, $14 \%$ thought a license was not required, and the rest thought a license was required. This suggests that a large share of customers choose professionals without knowing about the relevant regulations 19 One reason for this may be that customers simply trust that the existing regulations and their enforcement are enough to guarantee acceptable quality standards. We do find some support for this, with $53 \%$ of the respondents in favor of licensing regulation, and 16\% against it. In the next section we quantify how these regulations affect aggregate demand, competition, and equilibrium prices.

\section{Effect of Occupational Licensing Regulation on Market Outcomes}

In this section we study the aggregate effects of licensing stringency on competition, prices, and customer satisfaction. Aggregate effects from licensing - for both supply and demandmay arise even if, as our above results suggest, consumers do not consider the licensing status of individual providers in their choices. On the supply side, licensing laws may affect the decisions of individuals to become professionals in an occupation, and their bidding

\footnotetext{
${ }^{19}$ We were not able to confirm whether customers' beliefs in answering this question corresponded to reality; i.e. if a customer said that a license was required for the service requested, we could not always verify whether that was indeed the case.
} 
strategies. Non-licensed professionals may also change their quality due to competition from licensed professionals. Overall, to the extent that licensing regulation increases entry barriers, we should expect a negative effect of increased licensing stringency on the number of competing professionals. It is also possible that consumers do not take into account licensing information when choosing a service provider but rely instead on the existing regulatory framework to prevent unqualified individuals from operating. This seems in line with our survey evidence. If regulation increases consumer trust in service providers, it may also increase aggregate demand for the services covered by occupational licensing.

The advantage of studying how occupational licensing affects market outcomes in our context is twofold. First, the platform facilitates matching across a wide range of service categories and US states. To our knowledge, this level of breadth is unique in the literature on occupational licensing. Second, since the platform tracks requests, quotes, and, to some extent, hiring decisions and consumer evaluation of service quality, we can measure the effect of occupational licensing regulation on multiple stages of the consumer-professional exchange funnel: search, hiring, and ex-post satisfaction. We also observe many details about the job requests not available in prior studies on occupational licensing.

To evaluate the extent to which licensing regulation affects demand and supply, we exploit variation in the stringency of licensing requirements across states and service categories. Within each state-by-occupation cell, we form a measure of licensing stringency by combining data on occupational licensing regulation from the Institute for Justice with our own manually collected data. The Institute for Justice "License to Work" database (Carpenter et al. 2017) contains several dimensions of licensing requirements across all 50 states and the District of Columbia for 102 lower-income occupations ${ }^{20}$ For occupations not covered by this study, such as plumbers and electricians, we collect analogous information online and by phone from state government agencies.

The dimensions of licensing recorded in this data are fees, number of required exams, minimum grade for passing an exam, minimum age required before practicing, education requirements (expressed in years or credit hours), and experience requirements (in years). We reduce these dimensions to a one-dimensional stringency score for each state-occupation

\footnotetext{
${ }^{20}$ http://ij.org/report/license-work-2/.
} 
pair by taking the first element of a principal component on the full set of requirements. A higher score corresponds to more stringent regulation. We will refer to this score as licensing stringency. Table 3 displays the correlation between our measure of licensing stringency and each regulatory dimension included in the principal component analysis. The table shows that our measure of licensing stringency is indeed positively correlated with all dimensions of regulation, but especially with the number of required exams and fees ${ }^{21}$ The first principal component explains $47 \%$ of the variation in the dimensions of licensing regulation 22

Table 3: Licensing Regulation and Dimensionality Reduction.

\begin{tabular}{cc}
\hline Licensing Stringency & Correlation \\
\hline Days Lost & 0.852 \\
Education (Credits) & 0.072 \\
Education (Years) & 0.080 \\
Exams & 0.813 \\
Experience (Years) & 0.559 \\
Fees & 0.844 \\
Min Age & 0.741 \\
Min Grade & 0.290 \\
\hline
\end{tabular}

Notes: Correlations between the first principal component and the dimensions of occupational licensing regulation used in the principal component analysis. "Days Lost" is an estimate of how many days of work a professional loses to satisfy the occupational licensing requirements. This variable is computed by the Institute for Justice, so we do not have it for all occupations.

Before describing our estimation strategy and results, we discuss how our proxy for stringency regulation affects data selection. There are almost 400 home improvement categories defined by the platform, ranging from gutter cleaning and maintenance to pest control.

We associate each service category to a corresponding occupation. For example, "toilet installation" and "shower/bathtub repair" are categories associated with plumbers. Because our estimation relies on cross-state variation in licensing regulation for a single occupation

\footnotetext{
21 "Days Lost" is an estimate of how many days of work a professional loses to satisfy the occupational licensing requirements. It is included in the Institute for Justice database but not in the additional occupations for which we collected data. Adding it or removing it from the analysis does not change our results.

${ }^{22}$ Figure G.2 shows that our measure of licensing stringency is positively correlated with the share of bids from professionals with a verified license on the site. In the figure, we divide meta-category-zip code pairs into 20 quantiles according to the distribution of the licensing stringency variable. The y-axis shows the share of bids from professionals with a verified license. As licensing stringency increases, the share of bids from licensed professionals also increases. The correlation is relatively modest, implying that there are other factors influencing whether professionals choose to inform online consumers about their licensing status.
} 
we remove all categories that are not covered by occupational licensing regulation in any state, such as "gardening". Since a few occupations without state licensing regulation have local regulation (e.g. at a county or city level), which is hard to collect data on, we remove all state-occupation pairs without any state regulation 23 We further limit the sample to service groupings with at least 100 posted tasks in at least 10 states.24 At the state-occupation level, we have 375 groups, covering 44 states and 18 separate occupations.

To illustrate our licensing stringency measure, we highlight some examples. Pest control applicators in Oregon have a licensing stringency measure close to the average value of 0.18. The regulation requires professionals to be at least 18 years old, pay $\$ 206$ in licensing fees, and pass two exams. One standard deviation above the mean of the stringency measure yields a level of regulation corresponding to plumbers in Rhode Island. They have to be at least 22 years old, pay $\$ 737$, pass 2 exams, attend 5 hours of class instruction 25 and have five years of experience. Subtracting one standard deviation means reducing the level of regulation to the laws covering cement finishing or painting contractors in Massachusetts, who only need to pay $\$ 250$ to be able to work.

Licensing stringency is defined at the state-occupation level, but we consider narrower markets given that additional regulatory requirements may be added at the county or city level. We define a market at the level of a service category and zip code. For example, we consider services within "air conditioning" in zip code 02139 and services within "duct/vent" in zip code 02163 as separate, even if they are subject to the same regulation for HVAC contractors in Massachusetts. With this definition we have 269,084 markets in our data.

Table 4 shows task-level descriptive statistics for the market equilibrium variables at the search, hiring, and post-transaction phase. They include the number of quotes received by each task and the average quoted price for those tasks with fixed price bids, the hiring rate and the transaction price, the probability that the buyer gives the provider a 5-star

\footnotetext{
${ }^{23}$ For example, the states of Colorado, New York, Texas, and Wyoming do not have state-level licensing requirements for many occupations, but instead allow cities and counties to set their own standards.

${ }^{24}$ For this selection criterion, we first combine categories for similar services. For example, "solar panel installation" and "solar panel repair" are combined into a single "meta-category". With this definition, we limit the sample to meta-categories with at least 100 posted tasks in at least 10 states. We use this meta-category classification in Figure G.1 and Figures G.3 G.5.

${ }^{25} 37.5$ clock hours are equivalent to one semester credit, so 5 clock hours are equivalent to 0.13 semester credits (https://ifap.ed.gov/fregisters/FR102910Final.html, accessed in November 2019).
} 
review after hiring, and the buyer's probability to post another request on the platform. We observe a large degree of heterogeneity across service categories. With an average licensing stringency variable equal to 0.39 , requests tend to be posted in states and occupations with more stringent requirements than the average state-occupation level (0.18).

Table 4: Descriptive Statistics on Licensing Stringency and Equilibrium Outcomes.

\begin{tabular}{lcccccc}
\hline Variable & Observations & Mean & Standard Deviation & 10th Pctl. & Median & 90th Pctl. \\
\hline Licensing Stringency & 923,735 & 0.39 & 1.78 & -1.85 & 0.41 & 2.39 \\
Nr. Quotes & 923,735 & 1.9 & 1.51 & 0 & 2 & 4 \\
Avg. Fixed Quote $(\$)$ & 353,449 & 410.7 & 581.5 & 65 & 175 & 1,050 \\
Hire Probability & 740,734 & 0.17 & 0.37 & 0 & 0 & 1 \\
Fixed Sale Price (\$) & 58,129 & 239.2 & 382 & 50 & 125 & 500 \\
5-Star Review & 122,530 & 0.48 & 0.5 & 0 & 0 & 1 \\
Request Again & 122,530 & 0.23 & 0.42 & 0 & 0 & 1 \\
Request Again Diff. Cat. & 122,530 & 0.22 & 0.42 & 0 & 0 & 1 \\
\hline
\end{tabular}

Notes: Task-level descriptives. Row 1 and 2 include all tasks submitted in categories and states with some level of occupational licensing regulation. The following rows focus on a subset of these observations. Row 3 restricts attention to tasks with at least one fixed price quote. Row 4 focuses on any task with at least one offer. Row 5 focuses on the successful tasks whose winning bid includes a fixed price quote. Row 6,7 , and 8 focus on all successful tasks. "Request again" is equal to 1 if a customer posts another request at least one week after posting the current (successful) job. "Request again diff. cat." is equal to 1 if a customer posts another request in a service category that is different from the current job at least one week after posting the current job.

We first run regressions to evaluate the effect of licensing stringency on aggregate demand. Here we examine the possibility that, if regulation increases consumer trust in service providers by raising service quality, it may increase demand for the services provided by professionals covered by more stringent licensing regulation. We let $z$ denote a zip code, $c$ denote a category, and $t$ denote a month-year. We aggregate the number of requests at the category-zip code-year month level, and estimate the following equation:

$$
\begin{aligned}
& \log \left(\text { posted_requests } s_{c z t}\right)=\alpha \text { licensing_stringency } y_{\text {state }(z) \text { occupation }(c)}+ \\
& \mu_{z}+\mu_{c}+\mu_{t}+\epsilon_{c z t}
\end{aligned}
$$

We cluster standard errors at the state-occupation level. Results are presented in Table 5. The estimated effect is a relatively precise zero, suggesting that consumers do not post more requests on the platform for services that are covered by more stringent licensing regulation. This finding that aggregate demand on the platform does not appear to change 
with licensing stringency suggests that we can examine request-level outcomes as we study the equilibrium effects of licensing stringency driven by supply shifts.

Table 5: Cross-State Regression Estimates-Aggregate Demand

\begin{tabular}{lcccc}
\hline \hline & \multicolumn{4}{c}{$\log ($ Number of Requests) } \\
& $(1)$ & $(2)$ & $(3)$ & $(4)$ \\
\hline Licensing Stringency & -0.001 & $0.001^{*}$ & -0.0002 & -0.0002 \\
& $(0.001)$ & $(0.001)$ & $(0.001)$ & $(0.001)$ \\
& & & & \\
\hline Mean of Dependent Variable: & 0.065 & 0.065 & 0.065 & 0.065 \\
Category FE & No & Yes & Yes & Yes \\
Zip Code FE & No & No & Yes & Yes \\
Month-Year FE & No & No & No & Yes \\
Observations & $8,879,772$ & $8,879,772$ & $8,879,772$ & $8,879,772$ \\
$\mathrm{R}^{2}$ & 0.000 & 0.022 & 0.058 & 0.103 \\
\hline \hline
\end{tabular}

Notes: Regression results for aggregate demand Equation 3). An observation is a category-zip code-year month, and the outcome of interest is the number of posted requests. We augment the data to include all observations with no posted requests, although the results would not change if we only considered non-zero observations. Columns 2 through 4 increasingly add controls (category, zip code, and month-year fixed effects). Standard errors are clustered at the occupation-state level. ${ }^{*} \mathrm{p}<0.1 ;{ }^{* *} \mathrm{p}<0.05 ;{ }^{* * *} \mathrm{p}<0.01$.

To study the equilibrium effects from supply-side factors, we run regressions of the following form:

$$
y_{r}=\mu_{z(r)}+\mu_{c(r)}+\mu_{t(r)}+\beta \text { licensing_stringency } y_{\text {state }(r) \text { occupation }(c(r))}+\beta X_{r}+\epsilon_{r},
$$

where $r$ denotes a request, and each request has a corresponding category $c$, year-month $t$, and zip code $z$. In this regression, $X_{r}$ includes controls for how the customer was acquired (e.g. organic search or online advertising) and a small number of request characteristics (e.g. text length of the request). The variable $y_{r}$ is one of many possible outcome measures: at the search stage, our outcome variables include the number of quotes received and the average $(\log )$ quoted price for quotes with a fixed price bid; at the hiring stage, we use a dummy for whether a hire was recorded on the platform and the (log) transacted price for hires where the winning quote had a fixed price bid; at the post-transaction stage, we use a dummy for whether the consumer leaves a five-star review and a dummy for whether the consumer posts another request at least one week after the current request. ${ }^{26}$ Using data

\footnotetext{
${ }^{26}$ The one-week delay is to avoid confounding buyer's choice to post again on the platform with buyer's
} 
Table 6: Cross-State Regression Estimates

\begin{tabular}{|c|c|c|c|c|c|c|c|}
\hline & $\begin{array}{c}\text { Number } \\
\text { of Quotes } \\
(1)\end{array}$ & $\begin{array}{l}\text { Avg. Fixed } \\
\text { Quote (log) } \\
(2) \\
\end{array}$ & $(3)$ & $\begin{array}{l}\text { Fixed Sale } \\
\text { Price (log) } \\
\\
(4) \\
\end{array}$ & $\begin{array}{c}\text { 5-Star } \\
\text { Review } \\
(5) \\
\end{array}$ & $\begin{array}{l}\text { Request } \\
\text { Again } \\
(6) \\
\end{array}$ & $\begin{array}{c}\text { Request } \\
\text { Again } \\
\text { Diff. Cat. } \\
(7) \\
\end{array}$ \\
\hline $\begin{array}{l}\text { Licensing } \\
\text { Stringency }\end{array}$ & $\begin{array}{c}-0.024^{*} \\
(0.013) \\
\end{array}$ & $\begin{array}{c}0.022^{* * *} \\
(0.006) \\
\end{array}$ & $\begin{array}{l}-0.002 \\
(0.001) \\
\end{array}$ & $\begin{array}{c}0.018^{* * *} \\
(0.005) \\
\end{array}$ & $\begin{array}{c}0.001 \\
(0.002) \\
\end{array}$ & $\begin{array}{l}-0.002 \\
(0.001) \\
\end{array}$ & $\begin{array}{c}-0.002^{*} \\
(0.001) \\
\end{array}$ \\
\hline $\begin{array}{l}\text { Mean of Dep. Var. } \\
\text { Included Tasks }\end{array}$ & $\begin{array}{l}1.9 \\
\text { All }\end{array}$ & $\begin{array}{c}5.34 \\
\text { With Fixed } \\
\text { Quotes }\end{array}$ & $\begin{array}{c}0.17 \\
\text { With } \\
\text { Quotes }\end{array}$ & $\begin{array}{c}4.95 \\
\text { Hired a } \\
\text { Fixed Quote }\end{array}$ & $\begin{array}{c}0.48 \\
\text { Hired }\end{array}$ & $\begin{array}{c}0.23 \\
\text { Hired }\end{array}$ & $\begin{array}{c}0.22 \\
\text { Hired }\end{array}$ \\
\hline $\begin{array}{l}\text { Observations } \\
\mathrm{R}^{2}\end{array}$ & $\begin{array}{c}923,735 \\
0.525 \\
\end{array}$ & $\begin{array}{c}353,449 \\
0.505 \\
\end{array}$ & $\begin{array}{c}740,734 \\
0.081 \\
\end{array}$ & $\begin{array}{c}58,129 \\
0.581 \\
\end{array}$ & $\begin{array}{c}122,530 \\
0.128 \\
\end{array}$ & $\begin{array}{c}122,530 \\
0.148 \\
\end{array}$ & $\begin{array}{c}122,530 \\
0.148 \\
\end{array}$ \\
\hline
\end{tabular}

Notes: Regression results of equation 4 Zip code, month-year, and category fixed effects are included as controls. Column (1) includes all requests posted in categories and states with some level of occupational licensing regulation. The following columns focus on a subset of these observations. Column (2) restricts attention to requests with at least one fixed price quote. Column (3) focuses on any request with at least one offer. Column (4) focuses on the successful requests whose winning bid includes a fixed price quote. Column (5) through (7) focus on all successful requests. Standard errors are clustered at the state-occupation level. For category-specific estimates, see Figures G.3 through G.5 ${ }^{*} \mathrm{p}<0.1 ;{ }^{* *} \mathrm{p}<0.05 ;{ }^{* * *} \mathrm{p}<0.01$.

from eBay, Nosko and Tadelis (2015) showed that consumers draw conclusions about the quality of a platform from individual transactions, so we take the propensity to post again on the platform as a signal of consumer satisfaction about the service received by the hired professional.

Baseline regression results are in Table 6. On average, across all services, increases in occupational licensing stringency are associated with increases in quoted and transaction prices. The coefficient estimates imply that a one-standard-deviation increase in licensing stringency (1.78) decreases the number of quotes by 0.04 (or $2.2 \%$ ), increases quoted prices by $3.9 \%$, and increases transacted prices by $3.2 \%$. Licensing stringency does not significantly affect the hiring probability. More stringent licensing is also not associated with higher customer satisfaction, as measured by ratings or customer returns. If anything the coefficients are negative, although the point estimates are not economically significant.

The above analysis does not rule out possible compositional differences in the nature of jobs requested across states and occupations. For example, it might be the case that painting jobs in Arizona are for bigger houses than in Massachusetts, and so some of the decision to re-post an identical request. We can also restrict attention to posting again, but in a different service category. Results do not change. 
Table 7: Cross-State Regression Estimates - Double Machine Learning

\begin{tabular}{|c|c|c|c|c|c|c|c|}
\hline & $\begin{array}{c}\text { Number of } \\
\text { Quotes } \\
(1)\end{array}$ & $\begin{array}{l}\text { Avg. Fixed } \\
\text { Quote (log) } \\
(2)\end{array}$ & Hire & $\begin{array}{l}\text { Fixed Sale } \\
\text { Price (log) } \\
\\
(4)\end{array}$ & $\begin{array}{c}\text { 5-Star } \\
\text { Review } \\
(5)\end{array}$ & $\begin{array}{c}\text { Request } \\
\text { Again } \\
(6)\end{array}$ & $\begin{array}{c}\text { Request } \\
\text { Again } \\
\text { Diff. Cat. } \\
(7)\end{array}$ \\
\hline $\begin{array}{l}\text { Licensing } \\
\text { Stringency }\end{array}$ & $\begin{array}{c}-0.0221^{* * *} \\
(0.0012)\end{array}$ & $\begin{array}{c}0.0204^{* * *} \\
(0.0012)\end{array}$ & $\begin{array}{c}-0.0013^{* * *} \\
(0.0004)\end{array}$ & $\begin{array}{c}0.0177^{* * * *} \\
(0.0025) \\
\end{array}$ & $\begin{array}{c}0.0004 \\
(0.0013) \\
\end{array}$ & $\begin{array}{l}-0.0018^{*} \\
(0.0011) \\
\end{array}$ & $\begin{array}{l}-0.0018^{*} \\
(0.0011) \\
\end{array}$ \\
\hline Mean of Dep. Var. & 1.9 & 5.34 & 0.17 & 4.95 & 0.48 & 0.23 & 0.22 \\
\hline Included Tasks & All & $\begin{array}{c}\text { With Fixed } \\
\text { Quotes }\end{array}$ & $\begin{array}{l}\text { With } \\
\text { Quotes }\end{array}$ & $\begin{array}{c}\text { Hired a } \\
\text { Fixed Quote }\end{array}$ & Hired & Hired & Hired \\
\hline Observations & 923,735 & 353,449 & 740,734 & 58,129 & 122,530 & 122,530 & 122,530 \\
\hline $\mathrm{R}^{2}$ & 0.0004 & 0.0008 & 0.0000 & 0.0009 & 0.0000 & 0.0000 & 0.0000 \\
\hline
\end{tabular}

Notes: Double Machine Learning estimates of equation 4 (Chernozhukov et al. (2018)), where we use lasso to predict both treatment and outcome variable as a function of our explanatory variables. Point estimates, standard errors, and corresponding significance levels are based on the median across all splits. Standard errors are clustered at the state-occupation level. $\mathrm{R}^{2}$ and adjusted $\mathrm{R}^{2}$ are also based on the median across all splits. The observations included in each column are the same as in Table 6 Zip code, month-year, and category fixed effects are subject to lasso penalization just like the other explanatory variables. ${ }^{*} \mathrm{p}<0.1 ;{ }^{* *} \mathrm{p}<0.05 ;{ }^{* * *} \mathrm{p}<0.01$.

price differences that we capture with licensing stringency might in fact be a function of different task requests. To control for this possibility, we make use of the large set of questions that customers answer before posting a job, and flexibly control for their answers using the double machine learning estimator developed by Chernozhukov et al. (2018). This estimator predicts both the licensing stringency variable and the outcome variables as a function of all our observables constructed from geography, time, category, and task request details. For this prediction, we use Lasso regressions, and set the penalty parameter using 10-fold cross validation. For this prediction we split the data in two groups, training the model on one group to predict on the other. Then we use the predictions to regress the residual of our outcome variables on the residual of our licensing stringency variable. We do this 100 times ("splits"), and use the distribution of the resulting coefficients to get at our final estimate and standard errors.

The results displayed in Table 7 show the median estimated coefficients, and confirm the main conclusions drawn from Table 6, Furthermore, because these regressions use additional information from requests, they result in lower standard errors. The estimates from the double-ML procedure are nearly identical to our estimates from the fixed effects regressions. Even with the additional precision, we are not able to detect a statistically 
significant effect on measures of customer satisfaction 27

Before concluding this section, we explore heterogeneity of the effects of licensing regulation for different degrees of job complexity. Some states only regulate professionals if they perform jobs above a certain price threshold, and a natural dimension along which to measure heterogeneity in how licensing stringency affects outcomes is the expected price of a job ${ }^{28}$ We construct a proxy for the expected price of a given request by using a machine learning approach to predict whether the average quote submitted would be above a certain dollar threshold. We use price thresholds of $\$ 200, \$ 500$, and $\$ 1,000$. For each threshold, we construct the expected price as follows. First, we restrict the observations to requests that have at least one fixed price quote and we split this sample into five groups. For each group, we train a model to predict the average quoted price on the remaining $80 \%$ of the sample, and we use the prediction generated from this exercise as our predicted price for the focal group of observations. The right-hand-side variables used in this prediction exercise are request-level features, including a large vector of question-answer combinations about the nature of the task that the customer submits in response to a platform questionnaire when posting the request. Appendix Table G.8 demonstrates that our prediction performance is very high 29

We now use the predicted price for each job to see whether the effect of regulation on competition and prices is driven by larger and more complex jobs-defined as those jobs whose predicted price is above the $\$ 200, \$ 500$, or $\$ 1,000$ thresholds 30 Table 8 presents estimates of Equation 4 with licensing stringency interacted with a dummy variable for whether the job has a predicted price that is higher than a given threshold ( $\$ 200$ for the top panel, $\$ 500$ for the middle panel, and $\$ 1,000$ for the bottom panel). The reduction in the number of quotes seems similar across low- and high-priced jobs, but the price increase is mostly driven by the more complex jobs. Looking at column (4), we see that the interaction

\footnotetext{
27 Figure G.3 through Figure G.5 contain results on the effect of licensing stringency by service type.

${ }^{2} \mathrm{As}$ stated earlier, in California, painters are required to have an occupational license only if they perform jobs above $\$ 500$.

${ }^{29}$ For requests that have no fixed price quotes, we obtain a predicted price following a similar approach. We use the entire sample of requests with at least one fixed quote to train the model, and then use that trained model to predict prices from the request-level features of observations in the sample with no fixed price quotes.

${ }^{30}$ We do not see any effect of regulation stringency on aggregate demand for jobs whose price is higher than $\$ 200, \$ 500$, or $\$ 1,000$.
} 
Table 8: Heterogeneity by Price Point

\begin{tabular}{|c|c|c|c|c|c|c|c|}
\hline & $\begin{array}{c}\text { Number } \\
\text { of Quotes } \\
(1)\end{array}$ & $\begin{array}{l}\text { Avg. Fixed } \\
\text { Quote (log) } \\
(2) \\
\end{array}$ & $(3)$ & $\begin{array}{l}\text { Fixed } \\
\text { Sale Price } \\
\quad(\log ) \\
(4) \\
\end{array}$ & $\begin{array}{c}\text { 5-Star } \\
\text { Review } \\
(5) \\
\end{array}$ & $\begin{array}{l}\text { Request } \\
\text { Again } \\
(6) \\
\end{array}$ & $\begin{array}{c}\text { Request } \\
\text { Again } \\
\text { Diff. Cat. } \\
(7) \\
\end{array}$ \\
\hline Licensing Stringency & $\begin{array}{l}-0.016 \\
(0.015)\end{array}$ & $\begin{array}{l}0.013^{*} \\
(0.008)\end{array}$ & $\begin{array}{l}0.0001 \\
(0.002)\end{array}$ & $\begin{array}{c}0.010 \\
(0.006)\end{array}$ & $\begin{array}{c}-0.0002 \\
(0.002)\end{array}$ & $\begin{array}{c}-0.002^{*} \\
(0.001)\end{array}$ & $\begin{array}{c}-0.003^{*} \\
(0.002)\end{array}$ \\
\hline Licensing Str. ${ }^{*}>\$ 200$ & $\begin{array}{l}-0.015 \\
(0.014)\end{array}$ & $\begin{array}{l}0.024^{*} \\
(0.013)\end{array}$ & $\begin{array}{c}-0.003^{* *} \\
(0.002)\end{array}$ & $\begin{array}{c}0.035^{* * *} \\
(0.012)\end{array}$ & $\begin{array}{c}0.003 \\
(0.002)\end{array}$ & $\begin{array}{c}0.001 \\
(0.002)\end{array}$ & $\begin{array}{c}0.001 \\
(0.002)\end{array}$ \\
\hline $\mathrm{R}^{2}$ & 0.525 & 0.506 & 0.081 & 0.582 & 0.128 & 0.148 & 0.148 \\
\hline Licensing Stringency & $\begin{array}{c}-0.023^{*} \\
(0.014)\end{array}$ & $\begin{array}{l}0.018^{* *} \\
(0.007)\end{array}$ & $\begin{array}{l}-0.001 \\
(0.001)\end{array}$ & $\begin{array}{l}0.014^{* *} \\
(0.006)\end{array}$ & $\begin{array}{l}0.0003 \\
(0.002)\end{array}$ & $\begin{array}{c}-0.003^{* *} \\
(0.001)\end{array}$ & $\begin{array}{c}-0.003^{* *} \\
(0.001)\end{array}$ \\
\hline Licensing Str. ${ }^{*}>\$ 500$ & $\begin{array}{l}-0.004 \\
(0.017)\end{array}$ & $\begin{array}{c}0.030 \\
(0.025)\end{array}$ & $\begin{array}{l}-0.001 \\
(0.002)\end{array}$ & $\begin{array}{l}0.052^{*} \\
(0.028)\end{array}$ & $\begin{array}{c}0.005 \\
(0.003)\end{array}$ & $\begin{array}{l}0.004^{*} \\
(0.002)\end{array}$ & $\begin{array}{l}0.004^{*} \\
(0.002)\end{array}$ \\
\hline $\mathrm{R}^{2}$ & 0.525 & 0.506 & 0.081 & 0.582 & 0.128 & 0.148 & 0.148 \\
\hline Licensing Stringency & $\begin{array}{c}-0.025^{*} \\
(0.013)\end{array}$ & $\begin{array}{c}0.020^{* * *} \\
(0.007)\end{array}$ & $\begin{array}{l}-0.001 \\
(0.001)\end{array}$ & $\begin{array}{c}0.016^{* * *} \\
(0.005)\end{array}$ & $\begin{array}{c}0.001 \\
(0.002)\end{array}$ & $\begin{array}{c}-0.002^{*} \\
(0.001)\end{array}$ & $\begin{array}{c}-0.002^{*} \\
(0.001)\end{array}$ \\
\hline Licensing Str. $*^{*}>1,000$ & $\begin{array}{c}0.014 \\
(0.024)\end{array}$ & $\begin{array}{c}0.056 \\
(0.044)\end{array}$ & $\begin{array}{l}-0.003 \\
(0.002)\end{array}$ & $\begin{array}{l}0.120^{* *} \\
(0.058)\end{array}$ & $\begin{array}{l}0.008^{*} \\
(0.005)\end{array}$ & $\begin{array}{c}0.006 \\
(0.004)\end{array}$ & $\begin{array}{c}0.006 \\
(0.003)\end{array}$ \\
\hline $\mathrm{R}^{2}$ & 0.525 & 0.506 & 0.081 & 0.582 & 0.128 & 0.148 & 0.148 \\
\hline Observations & 923,735 & 353,449 & 740,734 & 58,129 & 122,530 & 122,530 & 122,530 \\
\hline
\end{tabular}

Notes: Three sets of regressions where the licensing stringency variable is interacted with a dummy variable for whether the predicted job price is above $\$ 200$ (top panel), $\$ 500$ (middle panel), or $\$ 1,000$ (bottom panel). Zip code, monthyear, and category fixed effects are included as controls. Everything else is identical to Table 6 Price predictions are done via machine learning using demand-side characteristics. Prediction performance metrics are shown in Table G.8 ${ }^{*} \mathrm{p}<0.1 ;{ }^{* *} \mathrm{p}<0.05 ;{ }^{* * *} \mathrm{p}<0.01$.

coefficient increases (and stays significant) as the price threshold increases. A one standard deviation increase in licensing stringency raises the price of jobs above $\$ 200$ by $6.2 \%$, it raises the price of jobs above $\$ 500$ by $9.3 \%$, and it raises the price of jobs above $\$ 1,000$ by 21.4\%. Thus, increases in licensing stringency are associated with higher prices especially for expensive jobs.

\section{Conclusion}

In this paper, we use new data collected by a digital platform to study the role of occupational licensing laws on individual choices and market outcomes. We first examine whether information about the professional's licensing status has an effect on consumer's choice of whom to hire. We find that consumers care about online reviews and prices more than about occupational licensing signals available on the platform. This result has several inter- 
pretations. The first interpretation is that occupational licensing may not be important for consumer decision making. The second interpretation is that consumers do not distinguish between licensed and unlicensed professionals because they believe that all professionals comply with relevant state regulation when bidding for a particular service, either by being licensed or by providing services of comparable quality to licensed professionals.

The previous result raises the question of whether licensing regulations actually improve service quality. If regulations do not improve quality, then consumers should rationally not care about licensing signals. If regulations do improve service quality, they may do so for even non-licensed providers due to competitive pressure. We exploit variation in licensing regulation across home improvement categories and across US states to study the marketlevel effects of licensing stringency. We find that licensing stringency is associated with fewer quotes and higher transaction prices but not better service, at least as measured through online reviews and propensity to use the platform again.

The paper has a number of limitations. In particular, services differ in the degree to which consumers have visibility into the dimensions of quality relevant for their safety. We proxy customer satisfaction with the propensity to use the platform again, and to positively rate the service providers. Both are likely to be noisy measures of provider quality. In addition, some consumer safety or professional quality issues may take time to manifest. For example, a consumer might not realize that a roofing contractor ignores basic safety measures when repairing a roof until much later-and potentially when it is too late to submit a review.

Another limitation of the study is that we address the population of primarily residential consumers who purchase online. If online consumers are less sensitive to licensing credentials, and service providers sort between online and offline customers accordingly, the effects measured in this paper do not necessarily extend to offline transactions. Our survey evidence suggests that licensing information is not important even for consumers who purchase home improvement services offline. We cannot say anything about the importance of licensing for commercial tasks relating to construction and home improvement since those are not in our data.

Both regulators and platforms have an interest in protecting consumers and ensuring 
service quality. Our results have implications for the design of licensing regulation and of digital platforms for services. In particular, the increased availability of alternative signals of quality, such as online reviews, has probably reduced the level of regulatory scrutiny needed for service providers. Furthermore, these signals may be useful in designing a more datadriven set of licensing regulations and enforcement mechanisms. Occupational licensing laws have also come into scrutiny from the Federal Trade Commission and the Department of Justice due to antitrust concerns (NC State Board of Dental Examiners v. FTC) and due to the role licensing laws may play in protecting consumers or in restricting competition. Our results suggest that, at least for the case of home improvement, more stringent licensing laws restrict competition but do not lead to noticeable improvements in quality.

For the platform, the lack of attention paid to verified licensing status by consumers suggests that the disclosure of status may be important. The broader ramifications of our findings for platform design hinge on whether the lack of consumer attention to licensing is caused by misinformed consumers, by the redundancy of licensing with reputational signals, or by the inability of licensing to ensure quality. Measuring the importance of these explanations requires more targeted research designs. We leave these questions for future investigation. 


\section{References}

Akerlof, G. A. (1970): "The Market for" Lemons": Quality Uncertainty and the Market Mechanism," Quarterly Journal of Economics, 488-500.

BARrios, J. M. (2019): "Occupational Licensing and Accountant Quality: Evidence from the 150-Hour Rule," Becker Friedman Institute for Research in Economics Working Paper 2018-32.

Blair, P. Q. And B. W. Chung (2018): "Job Market Signaling through Occupational Licensing," NBER Working Paper 24791.

Buonanno, P. And M. Pagliero (2019): "Occupational Licensing, Labor Mobility, and the Unfairness of Entry Standards," Working Paper, Collegio Carlo Alberto.

Carpenter, D. M., L. Knepper, A. C. Erickson, and J. K. Ross (2017): License to Work: A National Study of Burdens from Occupational Licensing, Institute for Justice.

Carroll, S. and R. Gaston (1981): "Occupational Restrictions and the Quality of Service Received: Some Evidence," Southern Economic Journal, 959-976.

Chen, D. L. And J. J. Horton (2016): "Research Note-Are Online Labor Markets Spot Markets for Tasks? A Field Experiment on the Behavioral Response to Wage Cuts," Information Systems Research, 27, 403-423.

Chen, Y. (2018): "User-Generated Physician Ratings: Evidence from Yelp," Working Paper, Stanford University.

Chernozhukov, V., D. Chetverikov, M. Demirer, E. Duflo, C. Hansen, W. Newey, And J. Robins (2018): "Double/Debiased Machine Learning for Treatment and Structural Parameters," The Econometrics Journal, 21, C1-C68.

Chevalier, J. A. And F. Scott Morton (2008): "State Casket Sales Restrictions: A Pointless Undertaking?" Journal of Law and Economics, 51, 1-23.

Cohen, P. (2016): "Moving to Arizona Soon? You Might Need a License," New York Times. 
Cowen, T. And A. TABarrok (2015): "The End of Asymmetric Information," Cato Unbound, 6 .

Cullen, Z. and C. Farronato (2015): "Outsourcing Tasks Online: Matching Supply and Demand on Peer-to-Peer Internet Platforms," Working Paper, Harvard University.

DePasquale, C. and K. Stange (2016): "Labor Supply Effects of Occupational Regulation: Evidence from the Nurse Licensure Compact," NBER Working Paper 22344.

Farronato, C. and G. Zervas (2019): "Consumer Reviews and Regulation: Evidence from NYC Restaurants," Working Paper.

Federman, M. N., D. E. Harrington, And K. J. Krynski (2006): "The Impact of State Licensing Regulations on Low-Skilled Immigrants: The Case of Vietnamese Manicurists," American Economic Review Papers and Proceedings, 96, 237-241.

Frandsen, B. R., L. J. Lefgren, And E. C. Leslie (2019): "Judging Judge Fixed Effects," NBER Working Paper 25528.

Friedman, M. (1962): Capitalism and Freedom, University of Chicago Press Chicago.

Hall, J., J. Hicks, M. M. Kleiner, And R. Solomon (2019): “Occupational Licensing of Uber Drivers," Working paper, University of Minnesota.

Harrington, D. E. And K. J. Krynski (2002): “The Effect of State Funeral Regulations on Cremation Rates: Testing for Demand Inducement in Funeral Markets," Journal of Law and Economics, 45, 199-225.

Horton, J. J. (2010): "Online Labor Markets," in International Workshop on Internet and Network Economics, Springer, 515-522.

Johnson, J. E. And M. M. Kleiner (2017): "Is Occupational Licensing a Barrier to Interstate Migration?" NBER Working Paper 24107.

Kleiner, M. And E. Soltas (2019): "A Welfare Analysis of Occupational Licensing in U.S. States," Working Paper, MIT. 
Kleiner, M. And M. XU (2019): "Occupational Licensing and Labor Market Fluidity," Working Paper, Queens University.

Kleiner, M. M. (2006): Licensing Occupations: Ensuring Quality or Restricting Competition?, Kalamazoo, MI: WE Upjohn Institute for Employment Research.

Kleiner, M. M. And A. B. Krueger (2010): "The Prevalence and Effects of Occupational Licensing," British Journal of Industrial Relations, 48, 676-687.

Kleiner, M. M. And R. T. Kudrle (2000): "Does Regulation Affect Economic Outcomes? The Case of Dentistry," Journal of Law and Economics, 43, pp. 547-582.

Koumenta, M. And M. Pagliero (2018): "Occupational Regulation in the European Union: Coverage and Wage Effects," British Journal of Industrial Relations.

Koumenta, M., M. Pagliero, And L. Dai (2019): "Occupational Regulation and Immigrant Wages: Evidence from the EU," Working paper, Queen Mary University of London.

Kugler, A. And R. M. Sauer (2005): "Doctors without Borders? Relicensing Requirements and Negative Selection in the Market for Physicians," Journal of Labor Economics, $23,437-465$.

Larsen, B. (2015): "Occupational Licensing and Quality: Distributional and Heterogeneous Effects in the Teaching Profession," Working Paper, Stanford University.

Law, M. T. And M. S. Marks (2009): "Effects of Occupational Licensing Laws on Minorities: Evidence from the Progressive Era," Journal of Law and Economics, 52, pp. $351-366$.

_ (2017): "The Labor-Market Effects of Occupational Licensing Laws in Nursing," Industrial Relations: A Journal of Economy and Society, 56, 640-661.

Leland, H. (1979): "Quacks, Lemons, and Licensing: A Theory of Minimum Quality Standards," Journal of Political Economy, 1328-1346.

LucA, M. (2016): "Reviews, Reputation, and Revenue: The Case of Yelp.Com," Working Paper, Harvard University. 
Maurizi, A. (1980): "The Impact of Regulation on Quality: The Case of California Contractors," in Occupational Licensure and Regulation, ed. by S. Rottenberg, Washington, DC: American Enterprise Institute for Public Policy Research, 299-333.

Millsap, A. (2017): "Some Progress On Occupational Licensing But Much More Needed," Forbes, available at https://perma.cc/MA97-Z34X.

Nosko, C. and S. Tadelis (2015): "The Limits of Reputation in Platform Markets: An Empirical Analysis and Field Experiment," NBER Working Paper 20830.

Pagliero, M. (2010): "Licensing Exam Difficulty and Entry Salaries in the US Market forLawyers," British Journal of Industrial Relations, 48, 726-739.

_ (2011): "What is the Objective of Professional Licensing? Evidence from the US Market for Lawyers," International Journal of Industrial Organization, 29, 473-483.

Pallais, A. (2014): "Inefficient Hiring in Entry-Level Labor Markets," American Economic Review, 104, 3565-3599.

Shapiro, C. (1986): "Investment, Moral Hazard, and Occupational Licensing," Review of Economic Studies, 53, 843.

SibiliA, N. (2017): "South Dakota Just Legalized Braiding Hair Without A License," Forbes.

Smith, A. (1776): An Inquiry into the Nature and Causes of the Wealth of Nations.

Timmons, E. J. (2017): "The Effects of Expanded Nurse Practitioner and Physician Assistant Scope of Practice on the Cost of Medicaid Patient Care," Health policy, 121, 189-196.

Timmons, E. J. And R. J. Thornton (2010): "The Licensing of Barbers in the USA," British Journal of Industrial Relations, 48, 740-757.

Traczynski, J. And V. Udalova (2018): "Nurse Practitioner Independence, Health Care Utilization, and Health Outcomes," Journal of Health Economics, 58, 90-109. 
Zumbrun, J. (2016): "Occupational Licenses May Be Bad for the Economy, But Good for Workers Who Have Them," Wall Street Journal, available at https://perma.cc/ X7QD-WPT9. 


\section{APPENDIX}

\section{A Additional Data and Analysis from Crawling Platform}

Our primary dataset analyzed in the body of the paper comes directly from the platform's internal databases, and several dimensions of professionals' profiles are omitted from this dataset, such as the actual text of these profiles. In 2018, we performed a web-crawling exercise to measure attributes that are unobserved in our primary sample. We identified the largest three cities for each state in terms of unique professionals in categories subject to licensing, and joined that list with the top 100 cities in terms of overall platform activity as measured by the number of requests. We excluded cities with fewer than 10 professionals in the city. For each category and city, we found the corresponding landing page for the platform. We then obtained information about all professionals displayed on the landing page and their reviews. This information included the professional's license status, ranking, name, number of hires, years in business, an indicator for whether he/she passed the platform's background checks without any negative information, photos, zip code, city, and an indicator of high engagement with the platform (similar to the "Superhost" badge on Airbnb). We also obtained the text that the professional added to his/her profile, and the professional's answers to commonly asked questions. Lastly, for each professional, we obtained all review text, dates, and ratings. In this Appendix we distinguish between onand off-platform reviews because reviews can come from services exchanged on or off the platform. If the review is submitted by a consumer who hired the professional through the platform it is denoted an on-platform review. Otherwise, it is an off-platform review.

In total, the crawl found 79,111 professionals whose profiles were displayed on at least one of the URLs corresponding to the landing page for an occupation in a given city. Table A.1 displays summary statistics for these professionals. The median professional in the sample has no hires, and one off-platform review. More detailed information is available if the customer clicks on the professional's profile. Conditional on being in the top five results for at least one URL, the median professional has 19 hires, 14 reviews, of which 12 are on-platform reviews, and a median average rating of 4.9 . $10 \%$ of professionals mention a 
license in their profile and $6 \%$ have a verified license ${ }^{31}$ Overall, $14 \%$ of professionals mention an occupational license in their profile, have a license verified by the platform, or both 32 Many professionals who mention a license in their online profile do not have it verified by the platform. This could be due to professionals intentionally not submitting their licenses for verification; some licenses being issued at a local level (the platform only verifies stateissued licenses); or some licenses being submitted but not yet verified ${ }^{33}$ Professionals also mention certifications ( $7 \%$ of the time) and insurance ( $12 \%$ of the time).

Table A.1: Summary Statistics Across Professionals in Web-Crawl Sample

\begin{tabular}{lccccccc}
\hline & Min & 25th Pct & Median & 75th Pct & Max & Mean & SD \\
\hline License Text & 0.00 & 0.00 & 0.00 & 0.00 & 1.00 & 0.10 & 0.30 \\
License Verified & 0.00 & 0.00 & 0.00 & 0.00 & 1.00 & 0.06 & 0.24 \\
Either License & 0.00 & 0.00 & 0.00 & 0.00 & 1.00 & 0.14 & 0.35 \\
Certification Text & 0.00 & 0.00 & 0.00 & 0.00 & 1.00 & 0.07 & 0.25 \\
Insurance Text & 0.00 & 0.00 & 0.00 & 0.00 & 1.00 & 0.12 & 0.32 \\
Background Check & 0.00 & 0.00 & 0.00 & 0.00 & 1.00 & 0.17 & 0.37 \\
Avg. Rating & 0.00 & 0.00 & 3.00 & 4.90 & 5.00 & 2.42 & 2.39 \\
Num. Reviews & 0.00 & 0.00 & 1.00 & 9.00 & 1327.00 & 10.77 & 31.75 \\
Total Hires & 0.00 & 0.00 & 0.00 & 9.00 & 2912.00 & 15.94 & 56.22 \\
\hline
\end{tabular}

Notes: This table displays summary statistics at a professional level from the web crawl sample. "License Text" refers to whether the word 'license' was mentioned in the profile text of a professional. "License Verified" refers to whether the pro has a license verified by the platform. "Either License" takes the value of 1 if the profile has license text or the license is verified. "Certification Text" and "Insurance Text" refer to whether the profile text mentions certifications or insurance. "Background Check" takes the value of 1 if the pro has passed a background check by the platform.

Table A.2 and Table A.3 display breakdowns of these statistics for the top 20 categories in terms of the number of professionals and in terms of the share of licensed professionals. $18 \%$ of professionals in the top category, "General Contracting", mention a license in their online profile, and $12 \%$ have a verified license. Categories that are more technical such as plumbing, home inspection, electrical wiring, and pest extermination top the list of the categories with the highest share of professionals with any licensing information. However,

\footnotetext{
${ }^{31}$ In particular, reviews can come from services exchanged on or off the platform. If the review is submitted by a consumer who hired the professional through the platform it is denoted an on-platform review. Otherwise, it is an off-platform review. Our main analysis in the body of the paper uses only on-platform reviews. See also Appendix D.

${ }^{32}$ Note that differences in the rates of verification between the crawl and platform sample can occur for many reasons including the fact that professionals differ in their propensity to bid and that the crawl was conducted during a different time period from the platform sample.

${ }^{33}$ In a manual investigation using websites of state licensing boards, we found it difficult to verify the validity of licenses of professionals who mentioned them in their profile. This could happen because the registered name of the professional differed from the name on the platform, because the license had expired, or because the professional held a different type of license than the one we were searching for.
} 
even in these categories, fewer than $50 \%$ of professionals disclose any credential and fewer than $28 \%$ mention a license. 


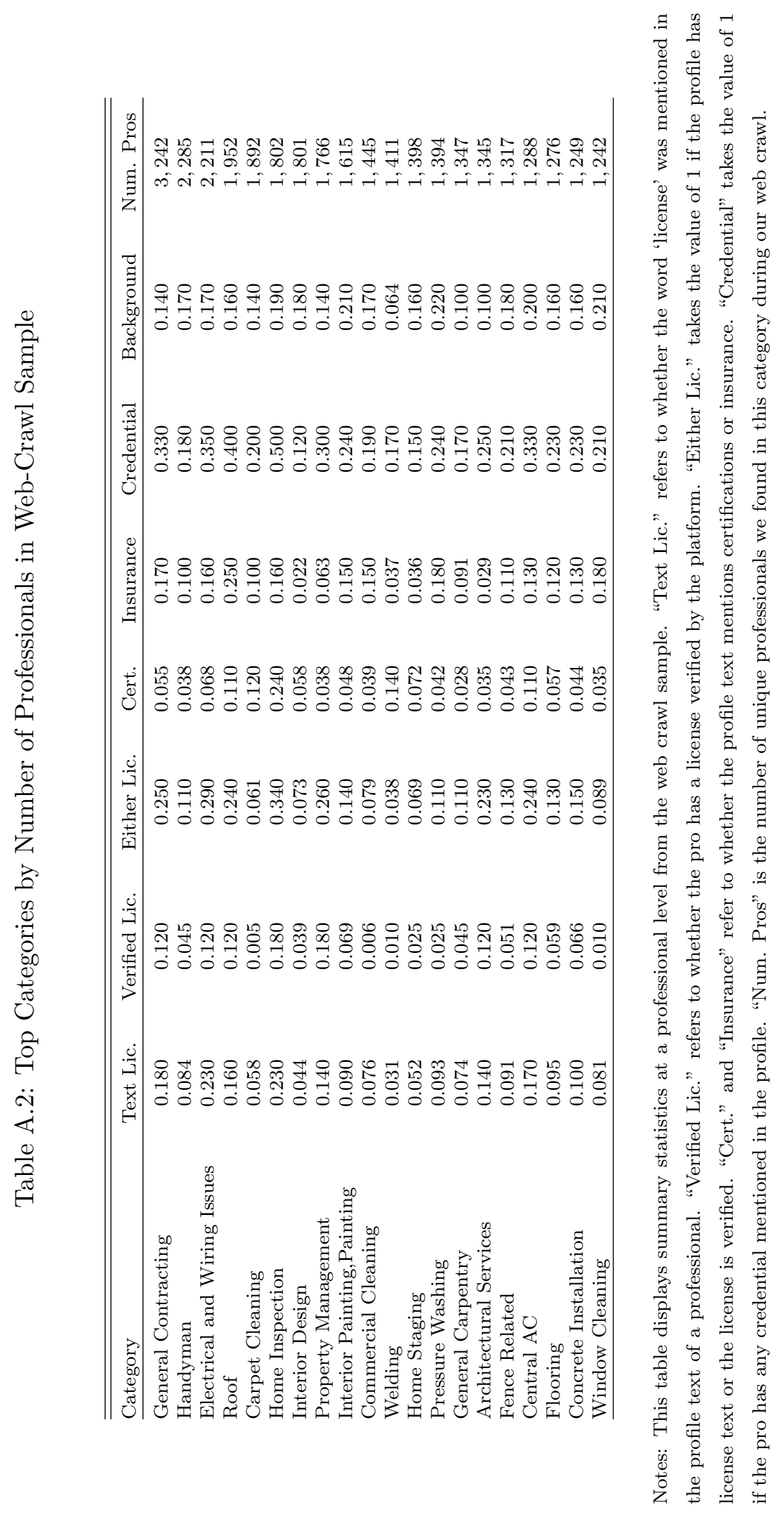




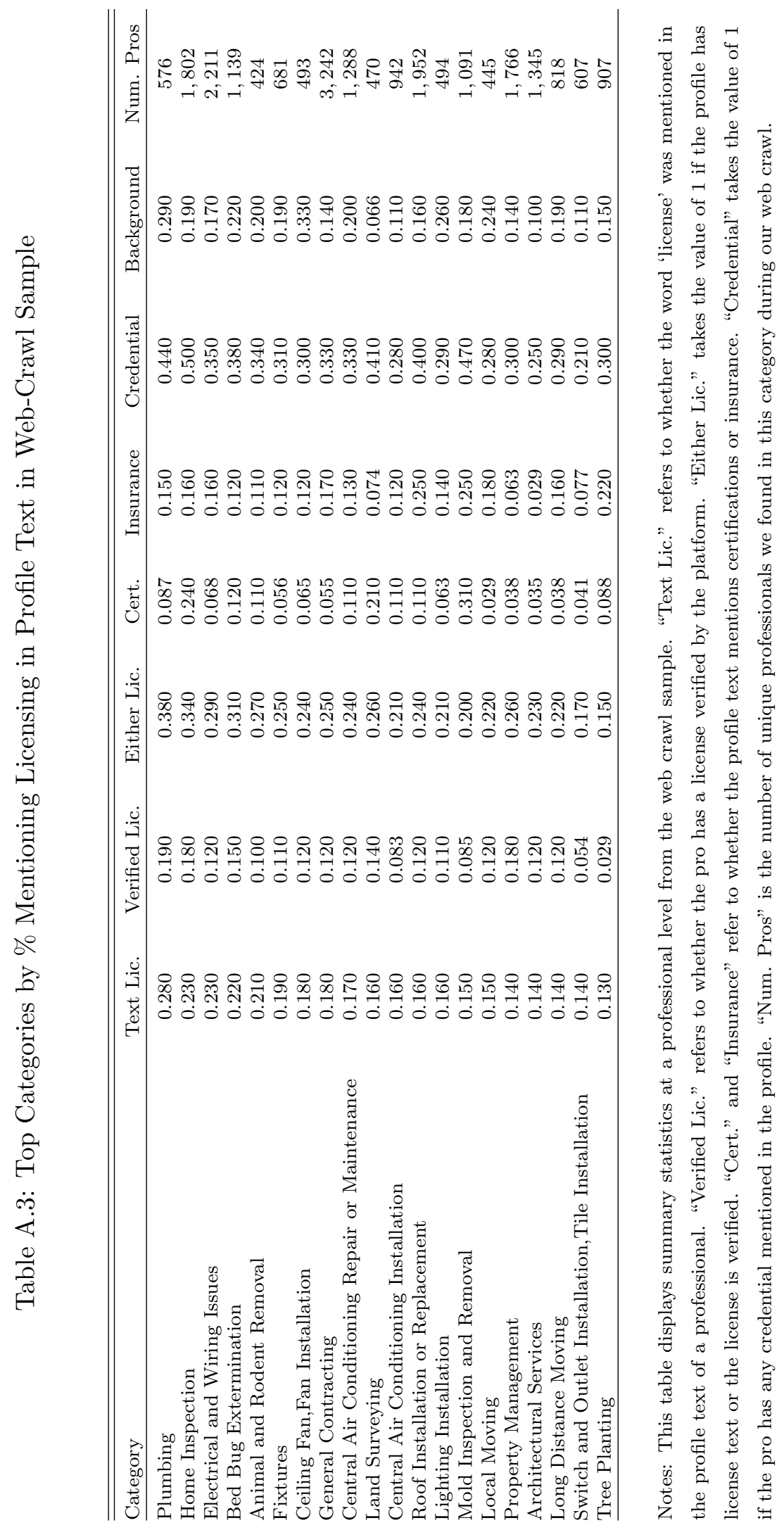




\section{B Analysis of California General Contractors}

One reason why professionals may not submit proof of their license for platform verification is that they are bidding on just the projects for which a license is not required. We examine this possibility here by studying general contractors in California. By California law, such professionals are allowed to perform general contractor jobs without a license as long as those jobs are below $\$ 500$. Figure B.1 displays the distribution of bids separately for professionals who had the platform verify their license, and for professionals who did not. The majority of bids for both types of professionals are below $\$ 500$. However, both platform-verified and never-verified professionals also bid above the $\$ 500$ threshold. This is consistent either with those professionals having a license that is not observable to us, or those professionals skirting some occupational licensing laws. Given our data, we cannot distinguish between these two alternatives.

Figure B.1: General Contractor Bids By Verified License Status (California)

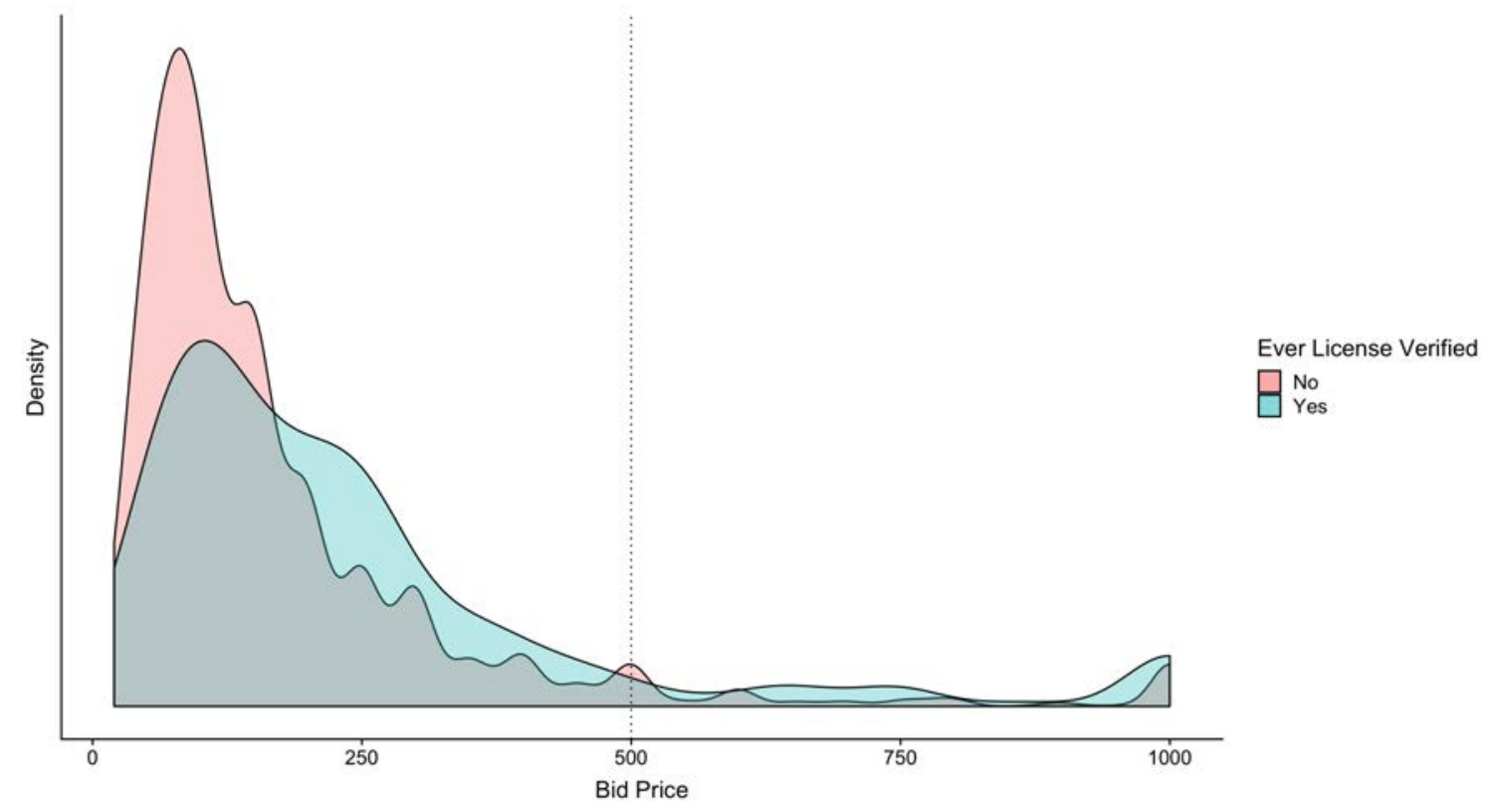

Notes: This figure presents the distribution of fixed prices bid for General Contractor requests in California. "Ever license verified" is a binary variable taking the value of 1 if we ever observe the professional having a platform verified license in the data. Prices are censored at 1000 to improve readability. 


\section{Additional Event Studies Related to License Verification}

In this section we discuss additional results regarding the event study design for license verification. We first investigate the possibility of heterogeneous treatment effects by whether the professional has a previous hire at the time of license verification. Professionals with a hire may find other ways to signal quality, reducing the need for the licensing signal, or the presence of a prior hire may serve as a substitute for licensing information. Figure C.1 displays the event study results where the time since license verification is interacted with whether the professional has a hire prior to the time of the bid. The point estimates suggest that, for professionals with no previous hires, hiring rates may increase after license verification, although the results are imprecise. We see no such result for professionals with a prior hire.

Figure C.1: Licensing Event Study - Heterogeneity

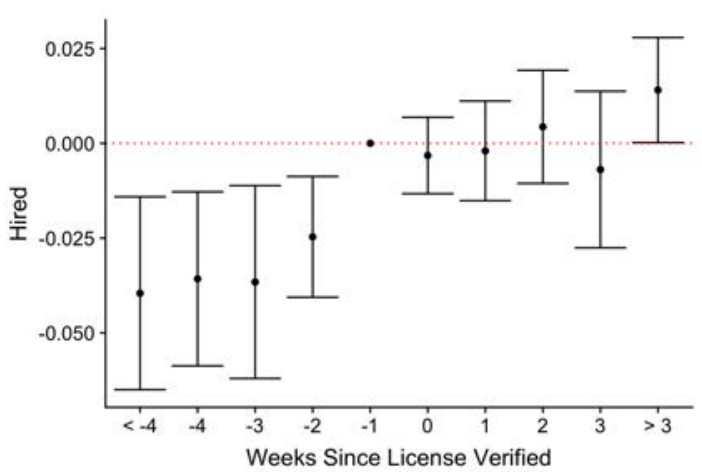

(a) Interaction: License * No Prior Hire

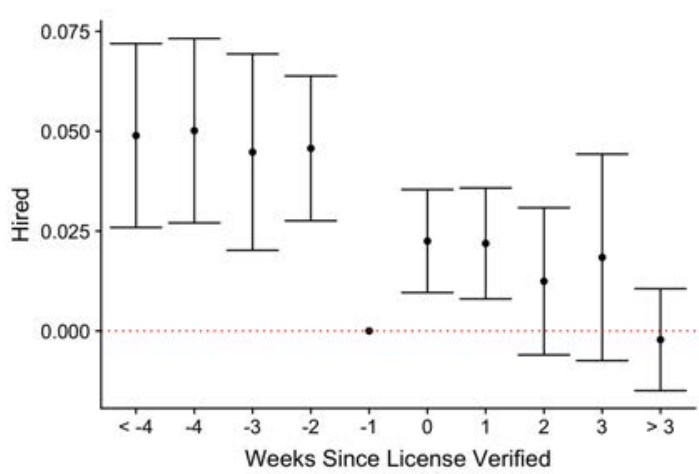

(b) Interaction: License ${ }^{*}$ Has Prior Hire

Notes: The figure is similar to Figure 2a except that we plot the coefficients on the interaction between license verification timing and either having no prior hire on the platform (left panel) or having a prior hire (right panel).

One reason why we may not detect an effect of licensing on hiring in our primary event study analysis is that professionals may adjust their bidding behavior around the time of the license verification. We show in subsection 3.1 that there is no evidence of this for the price that professionals bid. Below, we consider other margins of adjustment using the specification in Equation 1.

Figure $\overline{\text { C.2 }}$ a displays the number of quotes received on the requests that the professional 
bid on and C.2 b displays the average log prices of competitors faced by the professional. Both of these outcomes, which relate to the types of requests professionals bid on, don't vary with verified license status. Figure C.2 c displays an event study where the outcome is the order (relative to other bidders) in which a professional's bid arrives for a given request. There is no detectable effect of license verification status in the speed with which professionals bid on a request.

Lastly, we consider the number of bids submitted by professionals. Figure C.2 d displays the number of bids sent by a professional in the weeks around license verification, where we include a control for whether the license was submitted to the platform, as in our main event studies. We find that professionals decrease platform participation by 0.6 bids relative to a mean of 3.7 bids around the time of license verification. This is consistent with professionals increasing use of the platform, conducting many types of actions, and then reverting back to a baseline. 
Figure C.2: Licensing Event Study - Supply Side Responses

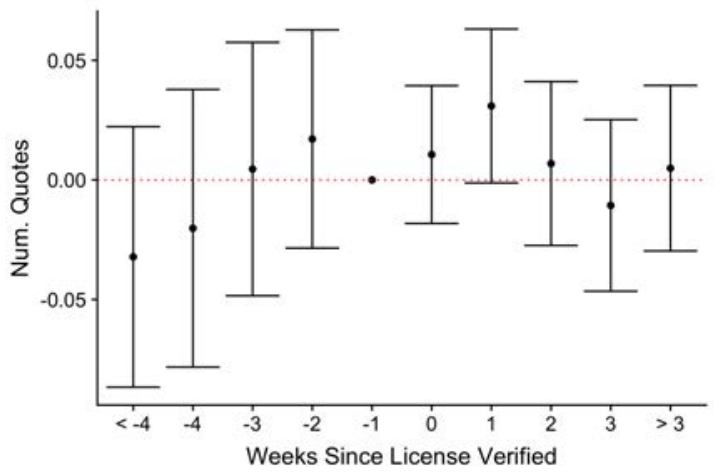

(a) Number of Other Bids on Request

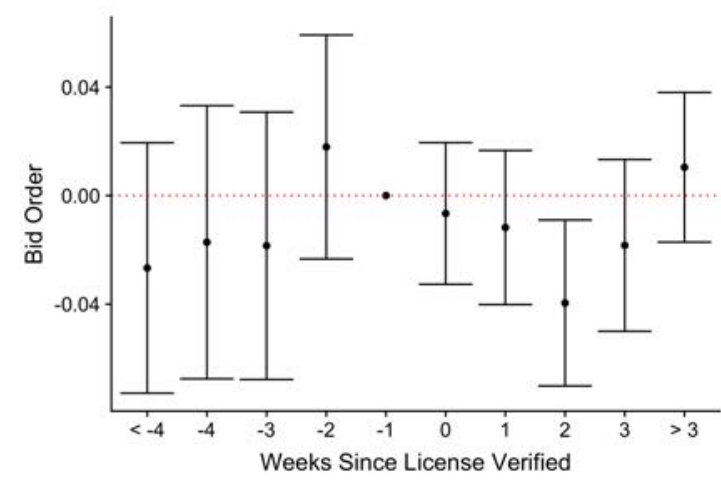

(c) Order of Bid Timing on a Request

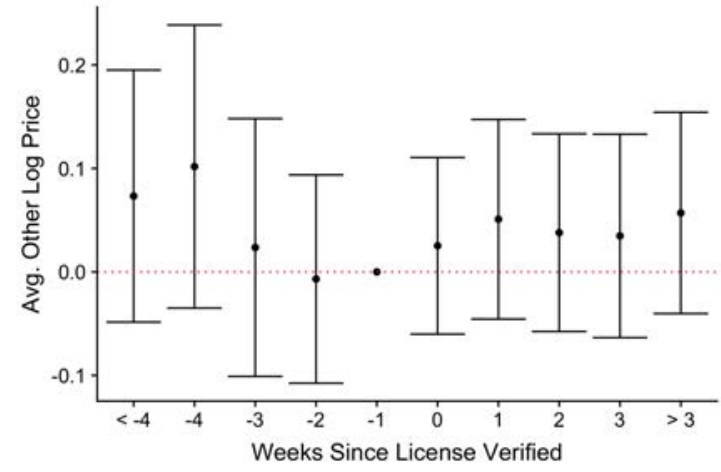

(b) Average Log Price of Other Bidders on Request

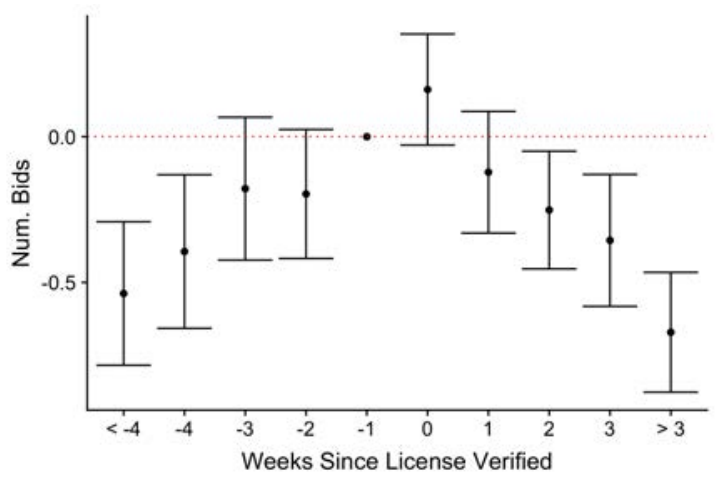

(d) Number of Bids by Professional

Notes: The figures plot estimates of Equation 1, where the outcome variable is one of the following: the number of competing quotes submitted to the request of the focal bid (top left panel); the average competing bid amount (top right panel); the order in which the focal bid was submitted to the request (bottom left); and the number of bids submitted in a given week by the focal professional (bottom right). 


\section{Additional Event Studies Related to First Reviews}

In this section we discuss additional results regarding the event study design for the first review. We first investigate the possibility of heterogeneous treatment effects by whether the review had a high rating and by whether the review was on-platform (see Appendix A for a description of on- vs. off-platform reviews). As a prior, we expect that the positive effect of first reviews on hiring comes from first reviews associated with high ratings. Furthermore, we would expect on-platform reviews to be more credible to consumers than off-platform reviews, and thus to have larger effects.

Figure D.1 displays the event study results for high- and low-rated first reviews. We find a large positive effect for high-rated reviews and no effect on hiring rates for low-rated reviews. We hypothesize that the lack of a negative effect of low-rated reviews is due to the fact that the baseline hiring rate of pros without reviews is already close to 0. Figure D.2 displays a similar contrast for on-platform reviews. There is a bigger and sharper jump in hiring rates for on-platform reviews, although the differences across the two review types are not statistically significant.

Figure D.1: First Review Event Study By Low vs. High Rating

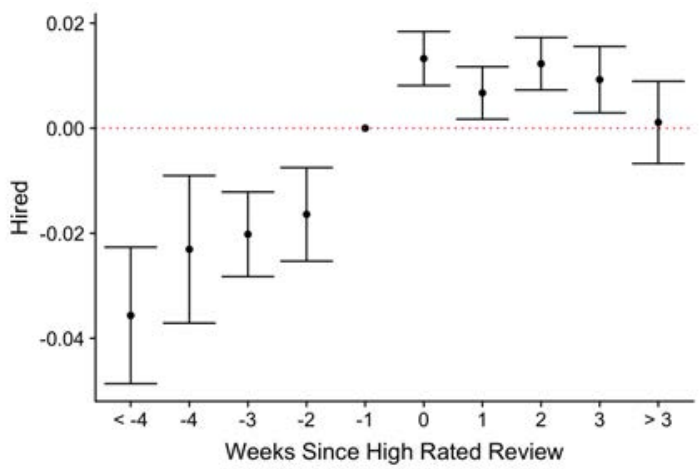

(a) Effect of First Review With Rating $\geq 4$

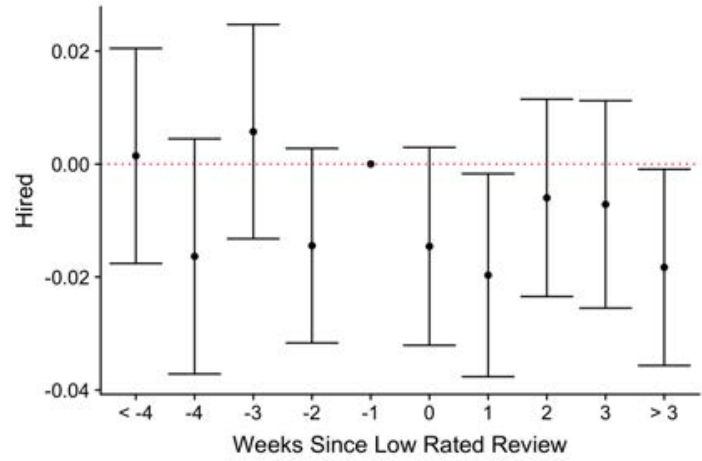

(b) Effect of First Review With Rating $<4$

Notes: The figure is similar to Figure 3a. except that we divide the sample in two groups: professionals with a first review with 4 or 5 stars (left panel), and professionals with a first review below 4 stars (right panel).

We now investigate whether the positive effect of the first review is driven by supply or demand side responses. Section 3.1 showed that there is no evidence of this for the price that 
Figure D.2: First Review Event Study - On-platform vs Off-platform

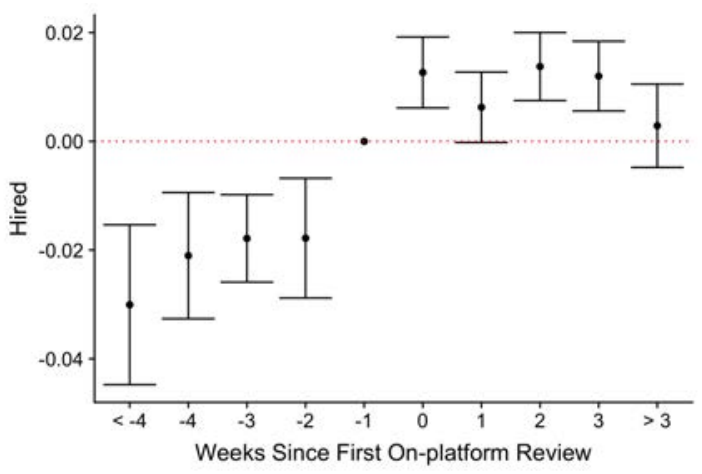

(a) Effect of On-platform First Reviews

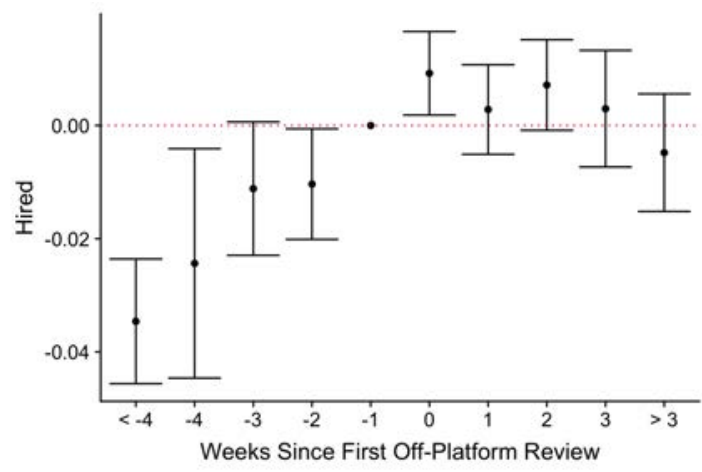

(b) Effect of Off-platform First Reviews

Notes: The figure is similar to Figure 3a except that we divide the sample in two groups: professionals whose first review was submitted by a consumer who hired the professional through the platform (left panel), and professionals whose first review was not submitted after a hire on the platform (right panel).

professionals bid. Below, we consider other margins of adjustment using the specification in Equation 1.

Figure D.3a displays the number of quotes received on the requests that the professional bid on and D.3b displays the average log prices of competitors faced by the professional. Both of these outcomes, which relate to the types of requests professionals bid on, do not change discontinously surrounding the arrival of the first review. Figure D.3. displays an event study where the outcome is the order (relative to other bidders) in which a professionals bid arrived for a given request. There is no detectable change on the speed with which professionals bid on requests immediately after the first review.

Lastly, we consider the number of bids submitted by professionals. Figure D.3d displays the number of bids sent by a professional in the weeks around the arrival of the first review. We find that professionals greatly increase bidding activity after obtaining the first review. This is, in principle, not a problem for our interpretation of the review effect on hiring being due to consumer demand. The reason is that although professionals increase their bidding frequency, the types of requests that are bid on and the prices of their bids do not greatly change due to the first review. 
Figure D.3: Review Event Study - Supply Side Responses

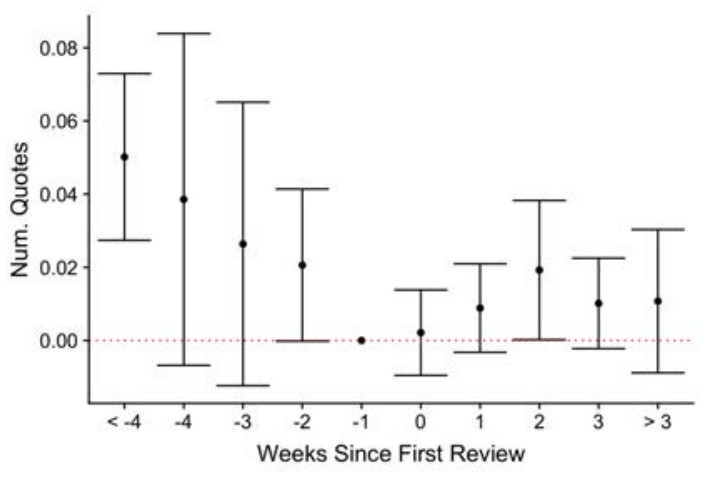

(a) Number of Other Bids on Request

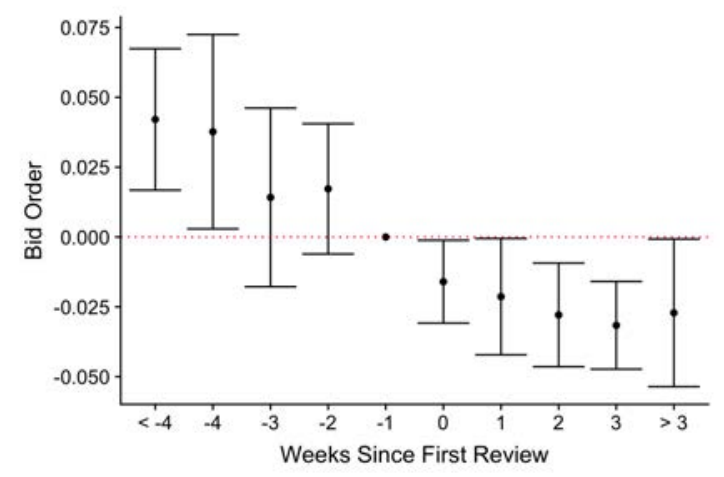

(c) Order of Bid Timing on a Request

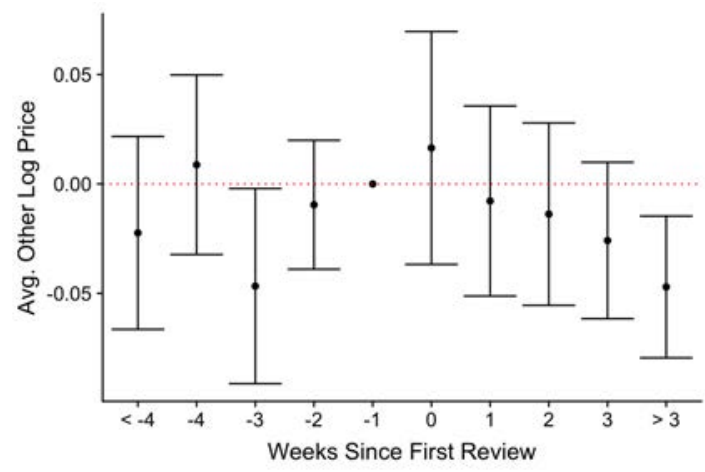

(b) Average Log Price of Other Bidders on Request

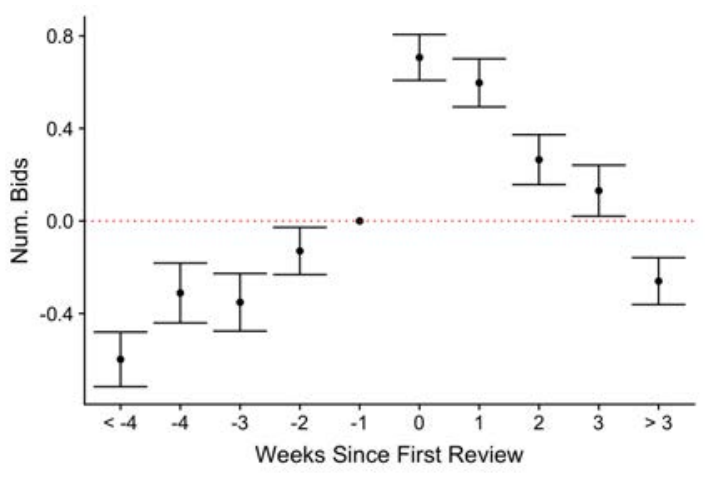

(d) Number of Bids by Professional

Notes: The figures plot estimates of Equation 1 where the event is the time when a professional receives their first review on the platform, and where the outcome variable is one of the following: the number of competing quotes submitted to the request of the focal bid (top left panel); the average competing bid amount (top right panel); the order in which the focal bid was submitted to the request (bottom left); and the number of bids submitted in a given week by the focal professional (bottom right). 


\section{E Construction of Ratings/Reviews Instruments}

Following Chen (2018), we instrument for a professional's rating using a measure of how lenient that professional's previous reviewers tend to be when rating other professionals (in any service category on the platform) ${ }^{34}$ The exclusion restriction this instrument must satisfy is that the leniency of a professional's previous reviewers does not directly affect the current customer's decision to hire the professional except through its effect on the professional's current rating. This argument appears to be quite reasonable in this context. For example, customers are unlikely to directly take such leniency into account, as it would require a great deal of searching on the platform for an individual user to learn how a given previous user rates other professionals. A violation of the exclusion restriction might occur if more lenient reviewers are attracted to professionals who are of higher (unobservable to the econometrician) quality, and hence are more likely to be hired by the current customer, but this seems unlikely in this context.

The leniency measure is constructed as follows. Let $R_{j r}$ represent the set of requests in which users rated professional $j$ before request $r$ is listed. For each request $\tilde{r} \in R_{j r}$, let $i(\tilde{r})$ (or simply " $i$ " for short) represent the identity of the consumer who rated $j$ on request $\tilde{r}$, and let $R_{i(\tilde{r}),-j}$ represent the set of requests on which user $i$ rated some professional other than $j$. We compute the average rating that consumer $i$ gives to professionals other than $j$ as

$$
\text { other_pro_rating }_{i(\tilde{r}),-j}=\frac{1}{\#\left\{R_{i(\tilde{r}),-j}\right\}} \sum_{s \in R_{i(\tilde{r}),-j}} \text { indiv_rating }_{i(\tilde{r}), s}
$$

where, in the summand, indiv_rating $g_{i(\tilde{r}), s}$ is the actual integer rating $i$ left on some request $s$, and the notation $\#\{\cdot\}$ represents the count of the elements in a set. We then construct the leniency instrument by averaging over all of these individual consumers' average ratings given to other professionals:

$$
\text { leniency }_{j r}=\frac{1}{\#\left\{\tilde{r} \in R_{j r}: R_{i(\tilde{r}),-j} \neq \emptyset\right\}} \sum_{\tilde{r} \in R_{j r}: R_{i(\tilde{r}),-j} \neq \emptyset} \text { other_pro_rating }_{i(\tilde{r}),-j}
$$

\footnotetext{
${ }^{34}$ This instrumentation strategy is related to but distinct from judge fixed effects leniency measures; see, for example, Frandsen et al. (2019) and references therein.
} 
In the case where a professional $j$ has no previous raters who are observed rating some other professional $-j$ at some point, we set leniency $y_{r}=0$. Our instruments for avg_rating $g_{j r}$ are leniency $_{j r}$ and a dummy for whether professional $j$ has any previous raters who have also rated other professionals (that is, a dummy for whether the leniency measure can be constructed).

We form an instrument for the number of previous reviews using a similar approach to that of the leniency instrument: we construct the propensity to review of consumers who have previously hired professional $j$. Let $H_{j r}$ represent the set of requests on which some user hired professional $j$ before request $r$ is listed. We wish to construct an instrument that captures the expected number of previous reviews we would predict for professional $j$ on request $r$ from knowing who $j$ 's previous hirers have been - and how likely they have been to review others whom they have hired. In constructing this instrument, we will take into account that some previous hirers may be slower than others in leaving reviews; that is, even if a previous hirer has not yet left a review, she may do so at some point 35

Similar to the instrument for average ratings, for each $\tilde{r} \in H_{j r}$, let $i(\tilde{r})$ represent the identity of the consumer who hired $j$ on request $\tilde{r}$, and let $H_{i(\tilde{r}),-j}$ represent the set of requests on which user $i$ hired some professional other than $j$. Also, let $t_{r, \tilde{r}}$ represent the amount of time (in days) between when the hired bid was posted for request $\tilde{r}$ and when $j$ 's bid on request $r$ was posted. Let

$$
P_{i(\tilde{r}), \tilde{r},-j}^{r}=\frac{1}{\#\left\{H_{i(\tilde{r}),-j}\right\}} \sum_{s \in H_{i(\tilde{r}),-j}} 1\left\{i(\tilde{r}) \text { leaves review within } t_{r, \tilde{r}} \text { days }\right\}
$$

We then construct the propensity-to-review instrument by averaging over all of these individual consumers' propensity to review other professionals they have hired:

$$
\text { propensity_to_review }_{j r}=\frac{1}{\#\left\{\tilde{r} \in H_{j r}: H_{i(\tilde{r}),-j} \neq \emptyset\right\}} \sum_{\left.\tilde{r} \in H_{j r}: H_{i(\tilde{r},-j}\right) \neq \emptyset} P_{i(\tilde{r}), \tilde{r},-j}^{r}
$$

In the case where a professional $j$ has no previous hirers who are observed hiring some

\footnotetext{
${ }^{35} \mathrm{~A}$ related point is that some consumers who hire a professional may not have time to leave a review before our main sample period ends. Fortunately, we observe data on ratings and reviews (but not bids and hiring decisions) for a full year following the ending of our main sample period, so this is not a concern.
} 
other professional at some point, we set propensity_to_review $w_{r}=0$. Our instruments for $\log \left(\right.$ reviews $\left._{j r}+1\right)$ (and for the dummy indicating that reviews $s_{r}=0$ ) and are then given by $\log \left(\right.$ propensity_to_review $\left._{j r}+1\right)$, a dummy for propensity_to_review $w_{j r}$ being equal to 0 , and a dummy for whether professional $j$ has any previous hirers who have also hired other professionals. The argument for the validity of this instrument is similar to that of the leniency measure: propensity will be a valid instrument unless consumers with a higher propensity to review are attracted to professionals who are of higher or lower quality (in a way that cannot be observed to the econometrician). We argue that this exclusion restriction is plausible in our context. 


\section{F Survey Questions}

Below is the set of questions asked in the survey of customers. The order of the answers was randomized at the respondent level. The order of the licensing questions was also randomized by block. Sometimes questions 9-10 appeared before questions 11-13, while other times questions 11-13 appeared first.

Q0 Have you hired someone to do home improvement services on your home in the past year? (For example painting, plumbing, electric services, interior design, heating or AC services, etc.)

$\square$ Yes

$\square$ No

Note: if "No", STOP survey.

Q1 When was the improvement done during the past year? Please select year and month: Drop-down menu with year-month options

Q2 What type of home improvement service did you need help with? Describe in a few words:

\section{Insert text}

Q3 Where was the home needing improvement located?

Drop-down menu with US states and territories

Q4 Did you own or jointly own the home where you needed the home improvement service?

Yes

$\square$ No

$\square$ Other. Please Specify:

Q5 How did you find the service provider? Select ALL that apply:

$\square$ Referral from a friend

$\square$ Search engine like Google

Yelp

Angie's List 
$\square$ Yellow Pages

$\square$ HomeAdvisor

$\square$ Thumbtack

Other. Please specify:

Q6 What are two or three reasons why you chose this service provider over other providers?

List the reasons from most important to least important.

Most important:

Second most important:

Third most important:

Q7 Approximately how much in total did you pay for this service?

Insert $\$$ amount

Q8 Approximately how many hours did the job take?

Insert numeric value

Q9 Did the service provider you hired have an occupational license?

$\square$ Yes

$\square$ No

$\square$ Not sure

Q10 How did you know whether the service provider you hired had an occupational license?

[Note: Question only made available to respondents who selected "Yes" to preceding question Q9].

$\square$ It was in the contract I signed.

He/She told me.

I saw it on Yelp, or a similar website.

I verified it on a government website.

Q11 Does the service provider you hired work in a profession for which occupational licensing is required by law in your geographic area?

Yes 
$\square$ No

Not sure

Q12 Do you think obtaining an occupational license in your geographic area for the service you requested is:

[Note: Question only made available to respondents who selected "Yes" or "Not sure" to preceding question $\mathbf{Q 1 1}$.

Easy, requiring little training beyond high-school.

$\square$ Moderately difficult, requiring some training and post-secondary education.

Difficult, requiring a lot of training and post-secondary education.

Not sure.

Q13a Suppose laws were to change so that an occupational license is no longer required for the home improvement services you requested. What would be your opinion of this change?

[Note: Question only made available to respondents who selected "Yes" to earlier question Q11].

$\square$ In favor

Opposed

$\square$ Indifferent

Q13b Suppose laws were to change so that an occupational license is required for the home improvement services you requested. What would be your opinion of this change?

[Note: Question only made available to respondents who selected "No" to earlier question Q11].

In favor

$\square$ Opposed

$\square$ Indifferent

Q13c What would be your opinion of a law requiring occupational licensing for the home improvement services you requested?

[Note: Question only made available to respondents who selected "Not sure" to earlier question Q11]. 
$\square$ In favor

$\square$ Opposed

$\square$ Indifferent

Q14 Do you work in the home improvement or construction industries?

$\square$ Yes

$\square$ No

Q15 What zip code do you currently live in?

Insert 5-digit code

Q16 What is your relationship status?

$\square$ Married

$\square$ Never Married

$\square$ Divorced

$\square$ Widowed

$\square$ Separated

Q17 How many children do you have that live at home with you or who you have regular responsibility for?

Insert integer number

Q18 What is your age?

Insert integer number

Q19 What is your gender?

$\square$ Female

$\square$ Male

Q20 Choose one or more races that you consider yourself to be:

$\square$ Spanish, Hispanic, or Latino

$\square$ Black or African American

Asian

$\square$ White 
American Indian or Alaska Native

$\square$ Native Hawaiian or Pacific Islander

Other. Please Specify:

Q21 Which statement best describes your current employment status?

Working (paid employee)

$\square$ Working (self-employed)

$\square$ Not working (retired)

$\square$ Not working (looking for work)

$\square$ Not working (disabled)

$\square$ Not working (temporary layoff from a job)

$\square$ Other. Please specify:

Q22 Which of the following industries most closely matches the one in which you are employed?

[Note: Question only made available to respondents who selected "Working (paid employee)" or "Working (self-employed)" to preceding question Q21].

Educational Services

Health Care and Social Assistance

Professional, Scientific, and Technical Services

$\square$ Retail Trade

$\square$ Finance and Insurance

$\square$ Manufacturing

$\square$ Construction

$\square$ Information

$\square$ Transportation and Warehousing

Other Services (except Public Administration)

Arts, Entertainment, and Recreation

$\square$ Public Administration

Accommodation and Food Services

Real Estate and Rental and Leasing 


\section{Utilities}

$\square$ Management of Companies and Enterprises

$\square$ Wholesale Trade

$\square$ Agriculture, Forestry, Fishing and Hunting

Administrative and Support and Waste Management and Remediation Services

$\square$ Mining, Quarrying, and Oil and Gas Extraction

$\square$ Other. Please specify:

Q23 Please describe your occupation:

[Note: Question only made available to respondents who selected "Working (paid employee)" or "Working (self-employed)" to earlier question Q21].

Insert text

Q24 Which category represents the total combined income of all members of your family in 2018? This includes money from jobs, net income from business, farm or rent, pensions, dividends, interest, social security payments and any other money income received.

Drop-down menu with income options

Q25 What is the highest level of school you have completed or the highest degree you have received?

Drop-down menu with education levels 


\section{G Additional Figures and Tables}

Table G.1: Sample Selection

\begin{tabular}{|c|c|c|c|c|c|c|}
\hline & $\begin{array}{c}\text { All } \\
\text { Requests }\end{array}$ & $\begin{array}{l}\text { Choice } \\
\text { Regres- } \\
\text { sions }\end{array}$ & $\begin{array}{l}\text { Cross-State } \\
\text { Regres- } \\
\text { sions }\end{array}$ & $\begin{array}{c}\text { E(Quoted } \\
\text { Price) }> \\
\$ 200\end{array}$ & $\begin{array}{l}\text { E(Quoted } \\
\text { Price) }> \\
\$ 500\end{array}$ & $\begin{array}{c}\text { E(Quoted } \\
\text { Price) }> \\
\$ 1,000\end{array}$ \\
\hline $\mathrm{N}$ & $4,073,310$ & 797,348 & 923,735 & 523,583 & 195,063 & 52,798 \\
\hline Number of bids & 2.17 & 2.35 & 1.90 & 1.96 & 2.22 & 2.48 \\
\hline Share with $\leq 1$ fixed quote & 0.53 & 0.40 & 0.38 & 0.29 & 0.27 & 0.27 \\
\hline Average fixed quote & 645.13 & 436.86 & 410.73 & 735.36 & $1,198.76$ & $1,716.17$ \\
\hline Hire probability & 0.19 & 0.17 & 0.17 & 0.13 & 0.11 & 0.13 \\
\hline Fixed sale price & 308.35 & $259.43 \dagger$ & 239.24 & 541.84 & 965.63 & $1,457.47$ \\
\hline 5-star review & 0.42 & 0.49 & 0.48 & 0.46 & $0.43 \dagger$ & $0.43 \dagger$ \\
\hline Request again & 0.22 & 0.19 & 0.23 & 0.22 & 0.23 & $0.22 \dagger$ \\
\hline \multicolumn{7}{|l|}{ Share by occupation: } \\
\hline Architect & 0.00 & 0.01 & 0.00 & 0.00 & 0.00 & 0.00 \\
\hline Asbestos Contractor & 0.00 & 0.00 & 0.00 & 0.00 & 0.00 & 0.00 \\
\hline Awning Contractor & 0.00 & $0.00 \dagger$ & 0.00 & 0.00 & 0.00 & 0.00 \\
\hline Carpenter & 0.03 & 0.05 & 0.07 & 0.10 & 0.01 & 0.00 \\
\hline Cement Finishing Contractor & 0.01 & 0.03 & 0.02 & 0.04 & 0.11 & 0.27 \\
\hline Door Repair Contractor & 0.01 & 0.02 & 0.02 & 0.01 & 0.00 & 0.00 \\
\hline Drywall Installation Contractor & 0.01 & 0.02 & 0.02 & 0.03 & 0.02 & 0.00 \\
\hline Electrician & 0.04 & 0.07 & 0.12 & 0.01 & 0.00 & 0.00 \\
\hline Flooring Contractor & 0.04 & 0.07 & 0.00 & 0.00 & 0.00 & 0.00 \\
\hline Foundation Repair & 0.00 & 0.00 & 0.00 & 0.00 & 0.00 & 0.00 \\
\hline General Contractor & 0.04 & 0.08 & 0.11 & 0.11 & 0.07 & 0.00 \\
\hline Glazier Contractor (Commercial) & 0.00 & $0.00 \dagger$ & 0.00 & 0.00 & 0.00 & 0.00 \\
\hline Glazier Contractor & 0.01 & 0.01 & 0.02 & 0.01 & 0.00 & 0.00 \\
\hline Handyman & 0.01 & 0.01 & 0.00 & 0.00 & 0.00 & 0.00 \\
\hline Home Entertainment Installer & 0.00 & 0.00 & 0.00 & 0.00 & 0.00 & 0.00 \\
\hline Home Inspector & 0.01 & 0.02 & 0.00 & 0.00 & 0.00 & 0.00 \\
\hline Household Goods Carrier & 0.01 & 0.00 & 0.00 & 0.00 & 0.00 & 0.00 \\
\hline HVAC Contractor & 0.01 & 0.03 & 0.03 & 0.02 & 0.02 & 0.05 \\
\hline Insulation Contractor & 0.00 & 0.00 & 0.00 & 0.00 & 0.00 & 0.00 \\
\hline Interior Designer & 0.02 & 0.00 & 0.01 & 0.01 & 0.00 & 0.00 \\
\hline Iron/Steel Contractor & 0.00 & $0.00 \dagger$ & 0.00 & 0.00 & 0.00 & 0.00 \\
\hline Land Surveyor & 0.00 & 0.00 & 0.00 & 0.00 & 0.00 & 0.00 \\
\hline
\end{tabular}

Notes: The table continues on the next page. 


\begin{tabular}{|c|c|c|c|c|c|c|}
\hline & $\begin{array}{c}\text { All } \\
\text { Requests }\end{array}$ & $\begin{array}{c}\text { Choice } \\
\text { Regres- } \\
\text { sions }\end{array}$ & $\begin{array}{c}\text { Cross-State } \\
\text { Regres- } \\
\text { sions }\end{array}$ & $\begin{array}{c}\text { E(Quoted } \\
\text { Price) }> \\
\$ 200\end{array}$ & $\begin{array}{l}\text { E(Quoted } \\
\text { Price) }> \\
\$ 500\end{array}$ & $\begin{array}{c}\text { E(Quoted } \\
\text { Price) }> \\
\$ 1,000\end{array}$ \\
\hline \multicolumn{7}{|l|}{ Share by occupation (continued): } \\
\hline Landscape Architect & 0.01 & 0.01 & 0.00 & 0.00 & 0.00 & 0.00 \\
\hline Landscape Contractor & 0.08 & 0.16 & 0.27 & 0.35 & 0.30 & 0.00 \\
\hline Lathing and Plastering Contractor & 0.00 & 0.00 & 0.00 & 0.00 & 0.00 & 0.00 \\
\hline Lead Inspector & 0.00 & 0.00 & 0.00 & 0.00 & 0.00 & 0.00 \\
\hline Locksmith & 0.00 & 0.00 & 0.00 & 0.00 & 0.00 & 0.00 \\
\hline Mason Contractor & 0.02 & 0.04 & 0.04 & 0.07 & 0.10 & 0.00 \\
\hline Mold Assessor & 0.01 & 0.01 & 0.00 & 0.00 & 0.00 & 0.00 \\
\hline None & 0.47 & 0.08 & 0.00 & 0.00 & 0.00 & 0.00 \\
\hline Painting Contractor & 0.05 & 0.09 & 0.07 & 0.12 & 0.25 & 0.48 \\
\hline Paving Contractor & 0.00 & 0.00 & 0.00 & 0.00 & 0.01 & 0.00 \\
\hline Pest Control Applicator & 0.03 & 0.06 & 0.11 & 0.06 & 0.00 & 0.00 \\
\hline Plumber & 0.02 & 0.04 & 0.06 & 0.03 & 0.07 & 0.20 \\
\hline Radon Contractor & 0.00 & 0.00 & 0.00 & 0.00 & 0.00 & 0.00 \\
\hline Real Estate Appraiser & 0.00 & 0.00 & 0.00 & 0.00 & 0.00 & 0.00 \\
\hline Roofing Contractor & 0.02 & 0.06 & 0.00 & 0.00 & 0.00 & 0.00 \\
\hline Sanitation System Contractor & 0.00 & $0.00 \dagger$ & 0.00 & 0.00 & 0.00 & 0.00 \\
\hline Security Alarm Installer & 0.00 & 0.01 & 0.01 & 0.02 & 0.03 & 0.00 \\
\hline Sheet Metal Contractor, Other & 0.00 & 0.01 & 0.01 & 0.01 & 0.01 & 0.00 \\
\hline Siding Contractor & 0.00 & 0.00 & 0.00 & 0.00 & 0.00 & 0.00 \\
\hline Solar Contractor & 0.00 & 0.00 & 0.00 & 0.00 & 0.00 & 0.00 \\
\hline Upholsterer & 0.01 & 0.00 & 0.00 & 0.00 & 0.00 & 0.00 \\
\hline \multicolumn{7}{|l|}{ Share by US region: } \\
\hline Northeast Region & 0.13 & 0.13 & 0.12 & 0.15 & 0.16 & 0.12 \\
\hline Midwest Region & 0.18 & 0.19 & 0.12 & 0.13 & 0.13 & 0.12 \\
\hline South Region & 0.44 & 0.44 & 0.44 & 0.39 & 0.36 & 0.32 \\
\hline West Region & 0.25 & 0.24 & 0.32 & 0.33 & 0.36 & 0.45 \\
\hline
\end{tabular}

Notes: The table shows descriptive statistics for requests in the various datasets used throughout the paper. The first column includes all Home Improvement requests. The second column includes the requests used in section 3 to study the role of occupational licensing information on consumer choices. The third through sixth column include the requests used in section 5 to study the market effects of more stringent licensing regulation. The data selection is described in section $2 \nmid$ denotes differences that are not significant from column 1 at standard confidence levels. The last three columns denote subsamples from the cross-state regression data (column 3) where $\operatorname{Pr}($ Average Fixed Quote $>$ X) $>0.5$ for thresholds $\$ 200, \$ 500$, and $\$ 1,000$ respectively. 
Table G.2: Alternative Choice Regressions - Pro FE and Logit: Outcome = Hired

\begin{tabular}{lcccccc}
\hline \hline & \multicolumn{2}{c}{ Linear Probability Model, Pro FE } & \multicolumn{3}{c}{ Conditional Logit Model } \\
& $(1)$ & $(2)$ & $(3)$ & $(4)$ & $(5)$ & $(6)$ \\
& OLS & Price IVs & All IVs & No IVs & Price IVs & All IVs \\
\hline License Submitted & 0.00214 & 0.00121 & $-0.0306^{* *}$ & 0.00820 & 0.00418 & 0.00995 \\
& $(0.00586)$ & $(0.0107)$ & $(0.0145)$ & $(0.00795)$ & $(0.00637)$ & $(0.00664)$ \\
License Verified & 0.00389 & 0.0120 & 0.0116 & 0.00697 & $0.0169^{* * *}$ & $0.0182^{* * *}$ \\
& $(0.00437)$ & $(0.0106)$ & $(0.0119)$ & $(0.00618)$ & $(0.00496)$ & $(0.00515)$ \\
& & & & & & \\
Average Rating & $0.0112^{* * *}$ & $0.00917^{* * *}$ & $-0.649^{* * *}$ & $0.0552^{* * *}$ & $0.0492^{* * *}$ & $0.280^{* * *}$ \\
& $(0.00162)$ & $(0.00316)$ & $(0.201)$ & $(0.00130)$ & $(0.00106)$ & $(0.0150)$ \\
Log(Reviews +1$)$ & $-0.0184^{* * *}$ & $-0.0261^{* * *}$ & $-0.0865^{* * *}$ & $0.0316^{* * *}$ & -0.000747 & $-0.00894^{* * *}$ \\
& $(0.00455)$ & $(0.00592)$ & $(0.0204)$ & $(0.000418)$ & $(0.000642)$ & $(0.000903)$ \\
Log(Price +1$)$ & $-0.0515^{* * *}$ & $-1.162^{* * *}$ & $-1.092^{* * *}$ & $-0.0421^{* * *}$ & $-0.666^{* * *}$ & $-0.607^{* * *}$ \\
& $(0.00800)$ & $(0.0783)$ & $(0.0726)$ & $(0.000595)$ & $(0.00913)$ & $(0.00931)$ \\
\hline$N$ & 2669083 & 2669083 & 2669083 & 2669083 & 2669083 & 2669083 \\
Other Controls & Yes & Yes & Yes & Yes & Yes & Yes \\
Request FE & Yes & Yes & Yes & Yes & Yes & Yes \\
Pro FE & Yes & Yes & Yes & No & No & No \\
\hline \hline
\end{tabular}

Notes: Columns 1-3 display results from estimating OLS regressions corresponding to columns 3, 5, and 7 from Table 2 but with professional fixed effect included. Standard errors are clustered at the professoinal level. First stage results for columns 2 and 3 are found in Table G.4 and Table G.7 Columns 4-6 display marginal effects from a conditional logit version of columns 3,5 , and 7 from Table 2 , where the grouping for the conditional logit model is done at the request level. The IV columns in the conditional logit model are estimated by first performing a first-stage regression of the endogenous variable(s) on the instruments and then controlling for the corresponding residuals from the first stage in the second stage. Note that conditional logit standard errors do not account for any clustering. ${ }^{*} \mathrm{p}<0.1$; ${ }^{* *} \mathrm{p}<0.05 ;{ }^{* * *} \mathrm{p}<0.01$. 
Table G.3: Choice Regressions - Interactions and Subsamples: Outcome = Hired

\begin{tabular}{|c|c|c|c|c|c|c|}
\hline & $(1)$ & $\overline{(2)}$ & $\overline{(3)}$ & $(4)$ & $(5)$ & $(6)$ \\
\hline License Submitted & $\begin{array}{c}-0.0499 \\
(1.116)\end{array}$ & $\begin{array}{l}0.00192 \\
(0.0121)\end{array}$ & $\begin{array}{l}-0.0222 \\
(0.0363)\end{array}$ & $\begin{array}{c}0.00616 \\
(0.00904)\end{array}$ & $\begin{array}{c}0.00507 \\
(0.00794)\end{array}$ & $\begin{array}{l}0.00310 \\
(0.0115)\end{array}$ \\
\hline License Verified & $\begin{array}{c}0.282 \\
(7.208)\end{array}$ & $\begin{array}{l}0.0232^{*} \\
(0.0133)\end{array}$ & $\begin{array}{c}0.0143 \\
(0.0210)\end{array}$ & $\begin{array}{c}0.0107 \\
(0.00928)\end{array}$ & $\begin{array}{c}0.0130 \\
(0.00856)\end{array}$ & $\begin{array}{c}0.0293^{* * *} \\
(0.0106)\end{array}$ \\
\hline Has Rating & $\begin{array}{c}-1.209^{* *} \\
(0.537)\end{array}$ & $\begin{array}{c}-1.245^{* *} \\
(0.516)\end{array}$ & $\begin{array}{c}-1.135^{* * *} \\
(0.377)\end{array}$ & $\begin{array}{c}-1.079^{* * *} \\
(0.386)\end{array}$ & $\begin{array}{c}-1.041^{* * *} \\
(0.362)\end{array}$ & $\begin{array}{c}-1.470^{* * *} \\
(0.559)\end{array}$ \\
\hline Average Rating & $\begin{array}{c}0.245 \\
(0.237)\end{array}$ & $\begin{array}{c}0.270^{* *} \\
(0.112)\end{array}$ & $\begin{array}{c}0.250^{* * *} \\
(0.0824)\end{array}$ & $\begin{array}{c}0.238^{* * *} \\
(0.0840)\end{array}$ & $\begin{array}{c}0.230^{* * *} \\
(0.0791)\end{array}$ & $\begin{array}{c}0.320^{* * *} \\
(0.121)\end{array}$ \\
\hline $\log ($ Reviews +1$)$ & $\begin{array}{l}0.00684 \\
(0.0558)\end{array}$ & $\begin{array}{r}-0.000157 \\
(0.00929)\end{array}$ & $\begin{array}{c}-0.000459 \\
(0.00568)\end{array}$ & $\begin{array}{l}-0.00357 \\
(0.00646)\end{array}$ & $\begin{array}{c}-0.00308 \\
(0.00595)\end{array}$ & $\begin{array}{c}0.0000183 \\
(0.00942)\end{array}$ \\
\hline $\log ($ Price +1$)$ & $\begin{array}{c}-0.632^{* *} \\
(0.260)\end{array}$ & $\begin{array}{c}-0.643^{* * *} \\
(0.0814)\end{array}$ & $\begin{array}{c}-0.614^{* * *} \\
(0.0469)\end{array}$ & $\begin{array}{c}-0.583^{* * *} \\
(0.0466)\end{array}$ & $\begin{array}{c}-0.569^{* * *} \\
(0.0447)\end{array}$ & $\begin{array}{c}-0.521^{* * *} \\
(0.0762)\end{array}$ \\
\hline License Submitted ${ }^{*}$ Has Rating & $\begin{array}{c}0.0726 \\
(1.780)\end{array}$ & & & & & \\
\hline License Verified ${ }^{*}$ Has Rating & $\begin{array}{c}-0.305 \\
(11.40)\end{array}$ & & & & & \\
\hline License Submitted * Stringency & & $\begin{array}{c}0.00517 \\
(0.00717)\end{array}$ & & & & \\
\hline License Verified $*$ Stringency & & $\begin{array}{c}-0.00214 \\
(0.00560)\end{array}$ & & & & \\
\hline License Submitted $*$ Price Tier $>200$ & & & $\begin{array}{c}0.0454 \\
(0.0498)\end{array}$ & & & \\
\hline License Verified * Price Tier $>200$ & & & $\begin{array}{r}-0.00348 \\
(0.0242)\end{array}$ & & & \\
\hline$N$ & 2669083 & 1368182 & 2650809 & 1706570 & 2250370 & 580568 \\
\hline Other Controls & Yes & Yes & Yes & Yes & Yes & Yes \\
\hline $\begin{array}{l}\text { Request FE } \\
\text { Consumer Never Posted Before }\end{array}$ & Yes & Yes & Yes & $\begin{array}{l}\text { Yes } \\
\text { Yes }\end{array}$ & Yes & Yes \\
\hline Consumer Never Hired Before & & & & Yes & Yes & \\
\hline $\begin{array}{l}\text { Request with } \geq 1 \text { Licensed } \\
\quad \text { and } \geq 1 \text { Non-licensed Pro }\end{array}$ & & & & & & Yes \\
\hline
\end{tabular}

Notes: Table displays alternative versions of specification 7 from Table 2 thus all columns show IV regressions using both price and reputation instruments. Regression in column 1 includes, as additional controls, the dummy for "Has Ratings" interacted with controls for the length of time since license submission and, as additional instruments, the interaction of these license submission timing controls with the dummy for the review propensity IV (see Appendix E being equal to zero. Stringency measure and predicted price measure used in columns 2 and 3, respectively, are described in Section 5 We omit first stage results to conserve space. Standard errors are clustered at the professional level. ${ }^{*} \mathrm{p}<0.1 ;{ }^{* *} \mathrm{p}<0.05 ;{ }^{* * *} \mathrm{p}<0.01$. 
Table G.4: First Stage Results of $\log ($ Price +1$)$

\begin{tabular}{lccc}
\hline \hline & $(1)$ & $(2)$ & $(3)$ \\
\hline Far Pro Distance & $-0.0589^{* * *}$ & $-0.0595^{* * *}$ & 0.00288 \\
& $(0.0154)$ & $(0.0151)$ & $(0.00812)$ \\
& & & \\
Same Location & $0.0494^{* * *}$ & $0.0517^{* * *}$ & $0.0317^{* * *}$ \\
& $(0.0101)$ & $(0.0141)$ & $(0.00574)$ \\
& & & \\
$\log ($ Distance +1$)$ & $0.0297^{* * *}$ & $0.0291^{* * *}$ & $0.0203^{* * *}$ \\
& $(0.00403)$ & $(0.00617)$ & $(0.00308)$ \\
\hline $\mathrm{N}$ & 2669083 & 2669083 & 2669083 \\
\hline \hline
\end{tabular}

Notes: Columns 1-2 displays first stage results corresponding to the IV regression from column 4-5 of Table 2 Column 3 displays the first stage regression corresponding to the IV regression in column 2 of Table G.2 Standard errors are clustered at the professional level. ${ }^{*} \mathrm{p}<0.1 ;{ }^{* *} \mathrm{p}<0.05 ;{ }^{* * *} \mathrm{p}<0.01$.

Table G.5: First Stage Results For IV Regression from Column 6 of Table 2

\begin{tabular}{lcccc}
\hline \hline & $(1)$ & $(2)$ & $(3)$ & $(4)$ \\
& Log(Fixed Price +1$)$ & Has Rating & Average Rating & Log $($ Reviews +1$)$ \\
\hline Far Pro Distance & $-0.0609^{* * *}$ & 0.0146 & 0.0887 & 0.0205 \\
& $(0.0154)$ & $(0.0101)$ & $(0.0529)$ & $(0.0350)$ \\
Same Location & $0.0488^{* * *}$ & $-0.0247^{* * *}$ & $-0.121^{* * *}$ & -0.00647 \\
& $(0.00982)$ & $(0.00410)$ & $(0.0204)$ & $(0.0123)$ \\
Log(Distance + 1) & $0.0299^{* * *}$ & $-0.00636^{* * *}$ & $-0.0363^{* * *}$ & 0.00150 \\
& $(0.00404)$ & $(0.00143)$ & $(0.00715)$ & $(0.00468)$ \\
Leniency & -0.00277 & 0.00117 & $0.0342^{*}$ & 0.00602 \\
& $(0.00647)$ & $(0.00273)$ & $(0.0147)$ & $(0.0133)$ \\
Leniency Calculable & 0.0226 & $0.109^{* * *}$ & $0.442^{* * *}$ & $0.244^{* * *}$ \\
& $(0.0311)$ & $(0.0153)$ & $(0.0795)$ & $(0.0658)$ \\
Log(Predicted Reviews +1$)$ & $-0.0594^{* * *}$ & -0.00195 & -0.0253 & $0.905^{* * *}$ \\
& $(0.0164)$ & $(0.00262)$ & $(0.0191)$ & $(0.0257)$ \\
Review Propensity Calculable & & $0.346^{* * *}$ & $1.575^{* * *}$ & $0.137^{* * *}$ \\
& -0.00368 & $(0.0110)$ & $(0.0546)$ & $(0.0290)$ \\
Review Propensity Calculable But $=0$ & $-0.0378^{* *}$ & $-0.0713^{* * *}$ & $-0.290^{* * *}$ & $0.323^{* * *}$ \\
$\mathrm{~N}$ & $(0.0121)$ & $(0.00741)$ & $(0.0389)$ & $(0.0271)$ \\
\hline \hline
\end{tabular}

Notes: The table displays first stage results for the IV regression in Column 6 of Table 2 Standard errors are clustered at the professional level. ${ }^{*} \mathrm{p}<0.1 ;{ }^{* *} \mathrm{p}<0.05 ;{ }^{* * *} \mathrm{p}<0.01$. 
Table G.6: First Stage Results For IV Regression from Column 7 of Table 2

\begin{tabular}{lcccc}
\hline \hline & $(1)$ & $(2)$ & $(3)$ & $(4)$ \\
& $\log ($ Fixed Price +1$)$ & Has Rating & Average Rating & Log(Reviews +1$)$ \\
\hline Far Pro Distance & $-0.0621^{* * *}$ & 0.00993 & 0.0648 & 0.0284 \\
& $(0.0153)$ & $(0.0100)$ & $(0.0525)$ & $(0.0346)$ \\
Same Location & $0.0515^{* * *}$ & $-0.0177^{* *}$ & $-0.0854^{* *}$ & 0.00330 \\
& $(0.0136)$ & $(0.00599)$ & $(0.0278)$ & $(0.0135)$ \\
Log(Distance + 1) & $0.0294^{* * *}$ & $-0.00444^{*}$ & $-0.0256^{* *}$ & 0.00513 \\
& $(0.00620)$ & $(0.00201)$ & $(0.00945)$ & $(0.00502)$ \\
Leniency & -0.00239 & 0.00269 & $0.0397^{* *}$ & 0.00811 \\
& $(0.00605)$ & $(0.00289)$ & $(0.0144)$ & $(0.0125)$ \\
Leniency Calculable & 0.0169 & $0.102^{* * *}$ & $0.412^{* * *}$ & $0.237^{* * *}$ \\
& $(0.0297)$ & $(0.0162)$ & $(0.0795)$ & $(0.0617)$ \\
Log(Predicted Reviews +1$)$ & $-0.0586^{* *}$ & -0.00174 & -0.0230 & $0.904^{* * *}$ \\
& $(0.0212)$ & $(0.00300)$ & $(0.0193)$ & $(0.0247)$ \\
Review Propensity Calculable & -0.00921 & $0.338^{* * *}$ & $1.535^{* * *}$ & $0.125^{* * *}$ \\
Review Propensity Calculable But $=0$ & $(0.0127)$ & $(0.0105)$ & $(0.0507)$ & $(0.0262)$ \\
$\mathrm{N}$ & $-0.0319^{*}$ & $-0.0697^{* * *}$ & $-0.283^{* * *}$ & $0.324^{* * *}$ \\
\hline \hline
\end{tabular}

Notes: The table displays first stage results for the IV regression in Column 7 of Table 2 Standard errors are clustered at the professional level. ${ }^{*} \mathrm{p}<0.1 ;{ }^{* *} \mathrm{p}<0.05 ;{ }^{* * *} \mathrm{p}<0.01$.

Table G.7: First Stage Results For IV Regression from Column 3 of Table G.2

\begin{tabular}{|c|c|c|c|c|}
\hline Far Pro Distance & $\begin{array}{c}(1) \\
\log (\text { Fixed Price }+1) \\
0.00268 \\
(0.00813)\end{array}$ & $\begin{array}{c}(2) \\
\text { Has Rating } \\
0.0122^{*} \\
(0.00501)\end{array}$ & $\begin{array}{c}(3) \\
\text { Average Rating } \\
0.0700^{* *} \\
(0.0239)\end{array}$ & $\begin{array}{c}(4) \\
\log (\text { Reviews }+1) \\
0.00552 \\
(0.0116)\end{array}$ \\
\hline Same Location & $\begin{array}{l}0.0318^{* * *} \\
(0.00574)\end{array}$ & $\begin{array}{c}-0.00583^{* * *} \\
(0.00150)\end{array}$ & $\begin{array}{c}-0.0267^{* * *} \\
(0.00715)\end{array}$ & $\begin{array}{l}-0.00223 \\
(0.00292)\end{array}$ \\
\hline $\log ($ Distance +1$)$ & $\begin{array}{l}0.0203^{* * *} \\
(0.00307)\end{array}$ & $\begin{array}{c}-0.00163^{* *} \\
(0.000497)\end{array}$ & $\begin{array}{c}-0.00647^{* *} \\
(0.00239)\end{array}$ & $\begin{array}{l}0.000811 \\
(0.00115)\end{array}$ \\
\hline Leniency & $\begin{array}{l}-0.00106 \\
(0.00320)\end{array}$ & $\begin{array}{l}-0.00348 \\
(0.00424)\end{array}$ & $\begin{array}{l}0.00364 \\
(0.0207)\end{array}$ & $\begin{array}{l}-0.0170^{*} \\
(0.00707)\end{array}$ \\
\hline Leniency Calculable & $\begin{array}{l}0.00438 \\
(0.0155)\end{array}$ & $\begin{array}{c}0.0813^{* * *} \\
(0.0203)\end{array}$ & $\begin{array}{l}0.293^{* *} \\
(0.0978)\end{array}$ & $\begin{array}{l}0.237^{* * *} \\
(0.0342)\end{array}$ \\
\hline $\log ($ Predicted Reviews +1$)$ & $\begin{array}{l}0.00107 \\
(0.00451)\end{array}$ & $\begin{array}{c}-0.0416^{* * *} \\
(0.00872)\end{array}$ & $\begin{array}{c}-0.235^{* * *} \\
(0.0374)\end{array}$ & $\begin{array}{r}0.662^{* * *} \\
(0.0321)\end{array}$ \\
\hline Review Propensity Calculable & $\begin{array}{c}-0.0214^{* * *} \\
(0.00452)\end{array}$ & $\begin{array}{l}0.324^{* * *} \\
(0.00814)\end{array}$ & $\begin{array}{l}1.530^{* * *} \\
(0.0383)\end{array}$ & $\begin{array}{l}0.201^{* * *} \\
(0.0120)\end{array}$ \\
\hline Review Propensity Calculable But $=0$ & $\begin{array}{c}0.00563 \\
(0.00389)\end{array}$ & $\begin{array}{l}-0.127^{* * *} \\
(0.00551)\end{array}$ & $\begin{array}{c}-0.589^{* * *} \\
(0.0260)\end{array}$ & $\begin{array}{c}0.0769^{* * *} \\
(0.0133)\end{array}$ \\
\hline $\mathrm{N}$ & 2669083 & 2669083 & 2669083 & 2669083 \\
\hline
\end{tabular}

Notes: The table displays first stage results for the IV regression in Column 3 of Table G.2 Standard errors are clustered at the professional level. ${ }^{*} \mathrm{p}<0.1 ;{ }^{* *} \mathrm{p}<0.05 ;{ }^{* * *} \mathrm{p}<0.01$. 
Figure G.1: Choice Regression (column 7 of Table 2) Separately by Meta-Category
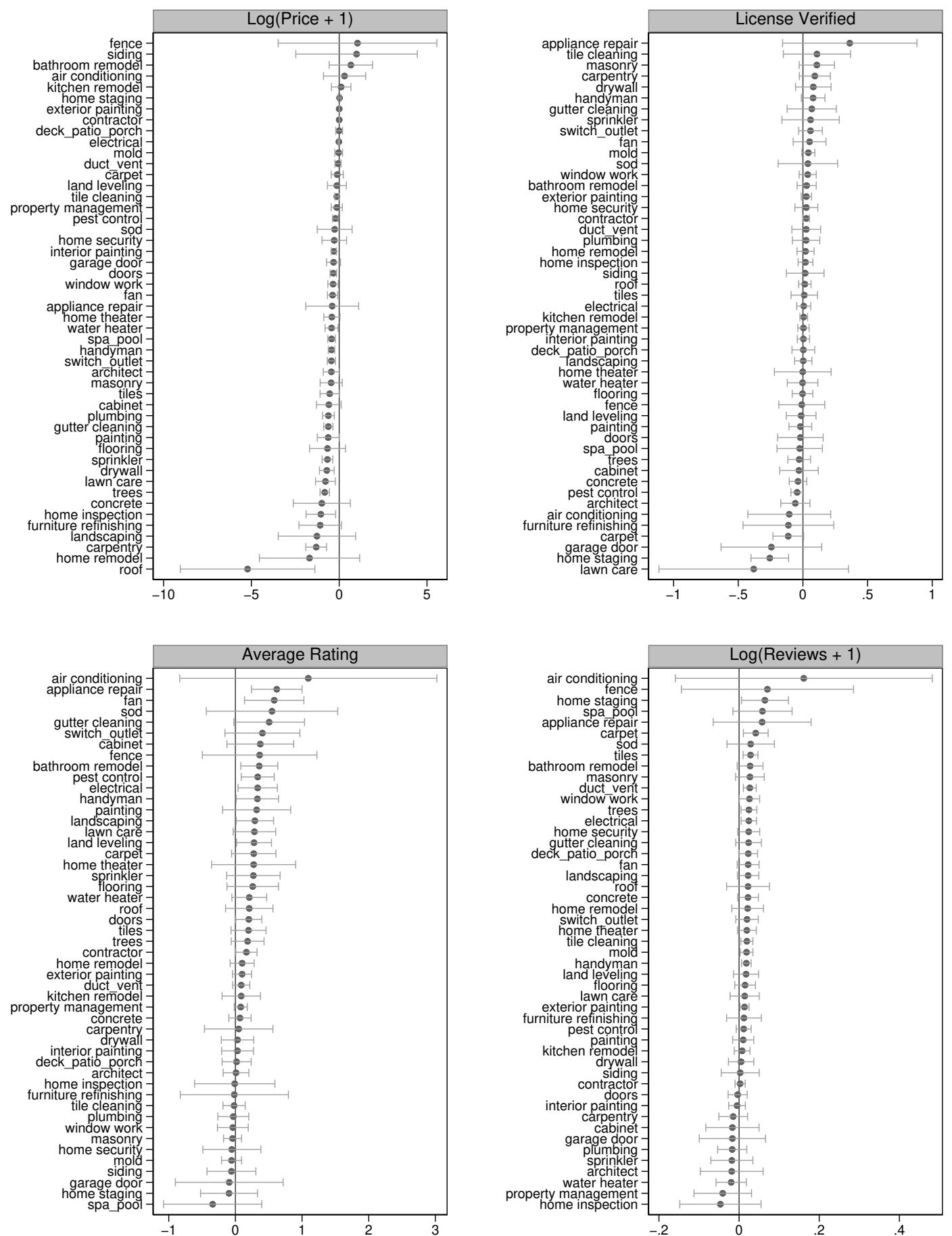

Notes: Key coefficients from estimating specification 7 from Table 2 separately by service meta-category. We manually define meta-categories by combining categories for similar services. For example, "solar panel installation" and "solar panel repair" are combined into a single "meta-category". The figure plots coefficient estimates for meta-categories with more than 10,000 bids. Standard errors are clustered at the professional level. $95 \%$ confidence intervals are shown in grey. 
Figure G.2: Licensing Stringency and Share of Licensed Professionals

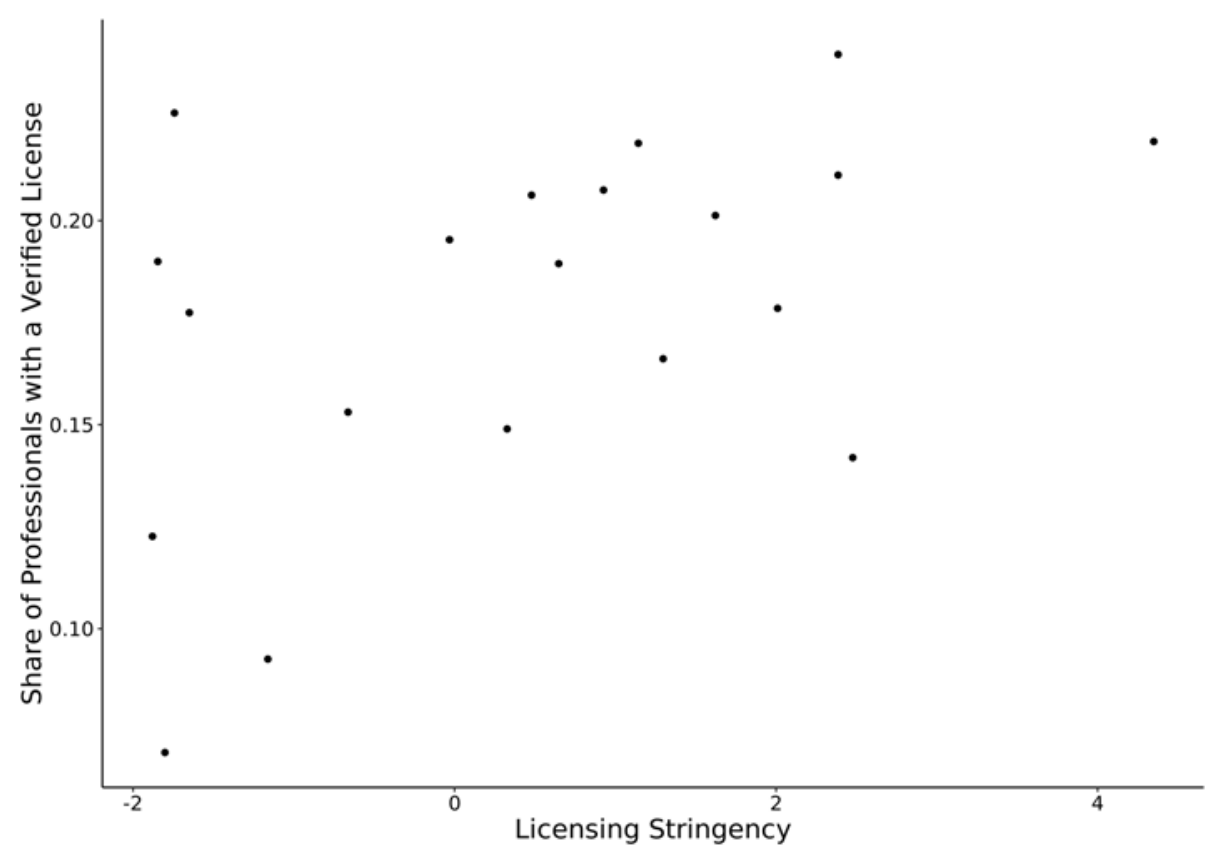

Notes: The figure plots how the share of professionals with a verified license on the platform varies with the stringency of occupational licensing regulation across states and occupations. We first manually define meta-categories by combining categories for similar services. For example, "solar panel installation" and "solar panel repair" are combined into a single "meta-category". For each zipcode-meta-category in our data we then compute the share of bids submitted by professionals with a verified license. We divide zipcode-meta-category level observations into the 20 quantiles of our licensing stringency measure (See section 5 for details on the construction of the licensing stringency variable). The figure is a binscatter plotting the average share of verified bids on the $y$-axis and the average licensing stringency variable on the $\mathrm{x}$-axis for each of the 20 bins. 


\section{Figure G.3: Meta-Category-Specific Effects of Licensing Stringency_Bidding Stage}

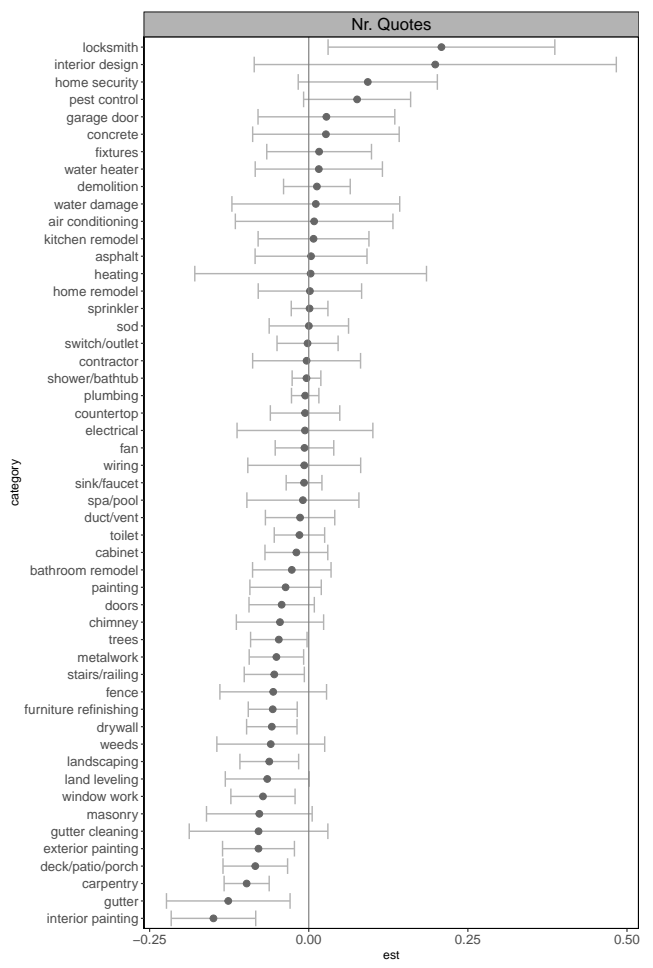

(a) Outcome: Number of Quotes

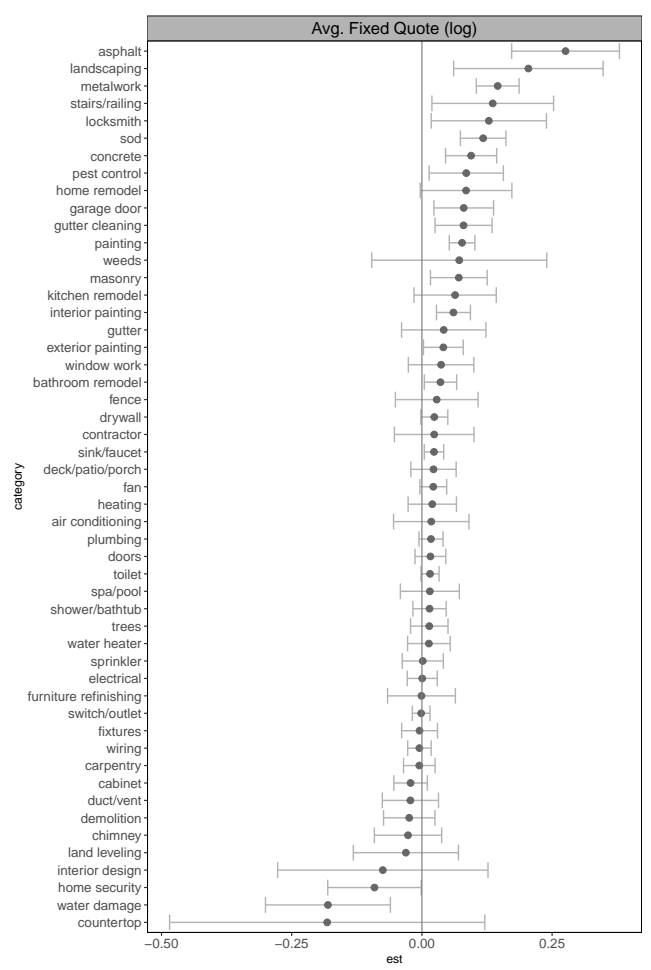

(b) Outcome: Log Average Fixed Quote

Notes: The figures plot the effects of licensing stringency from Equation 4 separately for each service meta-category. The dependent variable is the number of quotes received by a request (in the left panel) and the average log price of fixed price quotes (in the right panel). We manually define meta-categories by combining categories for similar services. For example, "solar panel installation" and "solar panel repair" are combined into a single "meta-category". $95 \%$ confidence intervals are plotted in grey. 


\section{Figure G.4: Meta-Category-Specific Effects of Licensing Stringency—Hiring Stage}

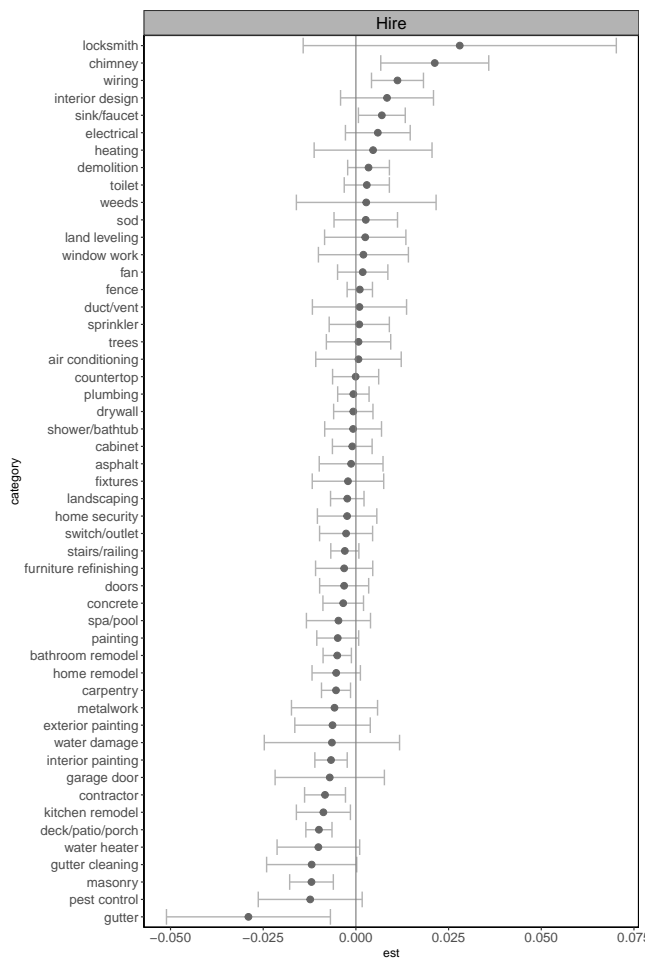

(a) Outcome: Hire

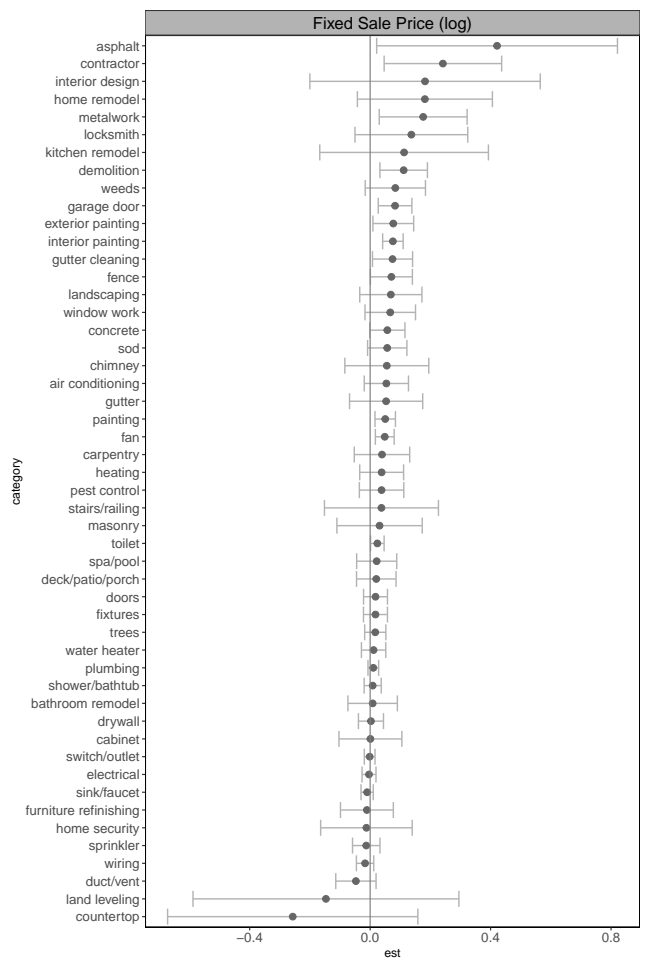

(b) Outcome: Log Fixed Sale Price

Notes: The figures plot the effects of licensing stringency from Equation 4 separately for each service meta-category. The dependent variable in the left panel is a dummy for whether a professional was hired for request $r$, conditional on receiving at least one quote, and in the right panel it is the (log) price of the winning quote for request $r$, when this quote was submitted with a fixed price bid. We manually define meta-categories by combining categories for similar services. For example, "solar panel installation" and "solar panel repair" are combined into a single "meta-category". $95 \%$ confidence intervals are plotted in grey. 
Figure G.5: Meta-Category-Specific Effects of Licensing Stringency-Post-Transaction Stage

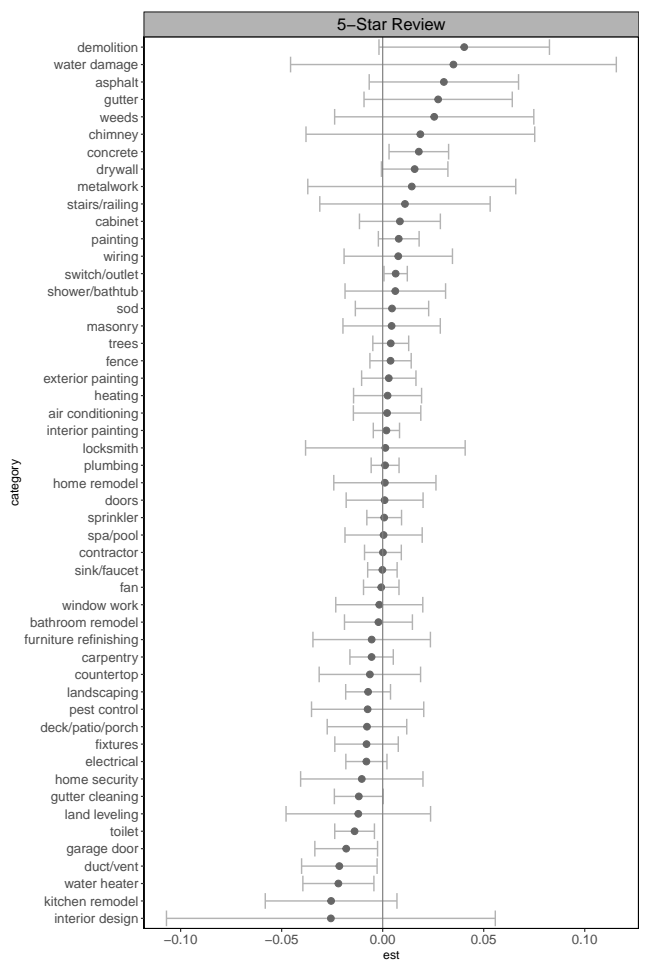

(a) Outcome: 5-Star Review

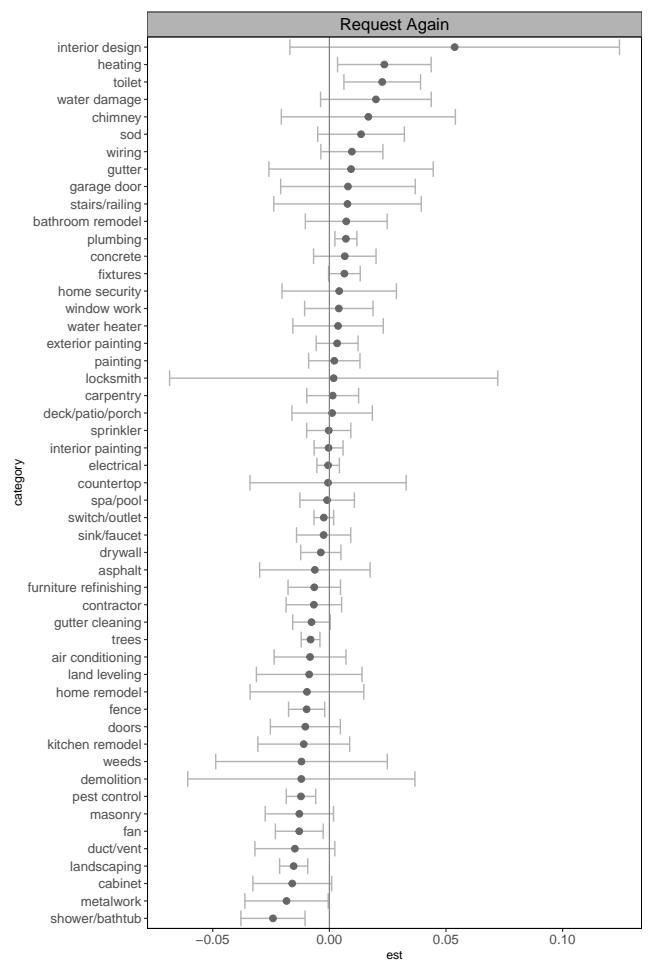

(b) Outcome: Customer Requests Again

Notes: The figures plot the effects of licensing stringency from Equation 4 separately for each service meta-category. In the left panel, the dependent variable is a dummy for whether a consumer left a five star review for the professional hired for request $r$. In the right panel, the dependent variable is a dummy for whether a consumer posted another request at least one week after posting the matched request $r$. We manually define meta-categories by combining categories for similar services. For example, "solar panel installation" and "solar panel repair" are combined into a single "meta-category". 95\% confidence intervals are plotted in grey. 
Table G.8: Confusion Matrices for Price Predictions

$\$ 200$ threshold

\begin{tabular}{lrrc}
\hline \hline Actual/Predicted & \multicolumn{1}{c}{0} & \multicolumn{1}{c}{1} & Total \\
\hline 0 & 293,555 & 68,841 & 362,396 \\
1 & 75,814 & 294,493 & 370,307 \\
Total & 369,369 & 363,334 & 732,703 \\
\hline
\end{tabular}

$\$ 500$ threshold

\begin{tabular}{lrrc}
\hline \hline Actual/Predicted & \multicolumn{1}{c}{0} & \multicolumn{1}{c}{1} & Total \\
\hline 0 & 537,388 & 29,897 & 567,285 \\
1 & 74,730 & 90,688 & 165,418 \\
Total & 612,118 & 120,585 & 732,703 \\
\hline
\end{tabular}

$\$ 1,000$ threshold

\begin{tabular}{lrrr}
\hline \hline Actual/Predicted & \multicolumn{1}{c}{0} & \multicolumn{1}{c}{1} & \multicolumn{1}{c}{ Total } \\
\hline 0 & 638,056 & 9,280 & 647,336 \\
1 & 57,862 & 27,505 & 85,367 \\
Total & 695,918 & 36,785 & 732,703 \\
\hline
\end{tabular}

Notes: Confusion matrices for price predictions. The top panel shows the number of requests with at least one fixed price quote, and divide them based on whether the actual fixed price quote is above $\$ 200$, and whether the predicted fixed price quote is above $\$ 200$. On the diagonal we have jobs for which the prediction matches reality. The middle panel does the same for a $\$ 500$ threshold, and the bottom panel for a $\$ 1,000$ threshold. AUC (area under the curve) performance measures are 0.880 (95\% C.I. 0.879-0.881), 0.902 (95\% C.I. 0.901-0.902), and 0.897 (95\% C.I. 0.896-0.898) for the three thresholds respectively. 